\title{
MUEBLES Y DECORADOS DE CINE: \\ LUIS M. FEDUCHI, LUIS SANTAMARÍA Y SU CONTRIBUCIÓN A LA PELÍCULA "EL BAILARÍN Y EL TRABAJADOR" (1936)
}

CINEMA FURNITURE AND SETS: LUIS M. FEDUCHI, LUIS SANTAMARÍA AND

THEIR CONTRIBUTION TO THE FILM: “THE DANCER AND THE WORKER” (1936)

\author{
Francisco Javier Muñoz-Fernández ${ }^{1^{*}}$ \\ Universidad del País Vasco/ Euskal Herriko Unibertsitatea
}

\section{Resumen}

Luis M. Feduchi y Luis Santamaría se encargaron de los decorados y el mobiliario de la comedia-musical de inspiración hollywoodiense "El bailarín y el trabajador" que Luis Marquina dirigió en 1936. Se trató de diseños realizados por los propios decoradores, que también utilizaron muebles de José Manuel Aizpúrua y Joaquín Labayen, así como sillas inspiradas en la casa Thonet. El filme se rodó, principalmente, en platós de cine por lo que el mobiliario fue el principal elemento para su ambientación; a la vez que le dotaron de un carácter moderno y dinámico, poco habitual en el cine español de la época, pero acorde con el carácter de la película.

Palabras clave: Luis M. Feduchi, Luis Santamaría, Aizpúrua-Labayen, Luis Marquina

\section{Abstract}

Luis M. Feduchi and Luis Santamaría made the sets and furniture for the Hollywood-inspired musical comedy "The Dancer and the Worker" directed by Luis Marquina in 1936. The decorators made their own designs, used furniture by José Manuel Aizpúrua and Joaquín Labayen, as well as chairs inspired by Thonet. As the film was mainly make in movie sets, furniture were essential and, at the same time, they gave a modern and dynamic character, unusual in the Spanish cinema at the time, but in relation to the character of the movie.

Keywords: Luis M. Feduchi, Luis Santamaría, Aizpúrua-Labayen, Luis Marquina

"El bailarín y el trabajador" de Luis Marquina fue una comedia-musical que se rodó en una época en la que la industria cinematográfica en España conoció un impulso decisivo gracias al desarrollo del cine sonoro. Se trató de la primera película del director y un proyecto ambicioso que se basó el cine de Hollywood, al que sumó una comedia del célebre dramaturgo Jacinto Benavente, que supo adaptar de manera ingeniosa, y la música del compositor de zarzuelas y obras 
de revista del igualmente conocido Francisco Alonso. Asimismo, contó con la participación de las principales estrellas del celuloide en España, como Roberto Rey, Ana María Custodio y Antoñita Colomé, que provenían del teatro y tenían experiencia en las versiones españolas de filmes norteamericanos. Mientras que los decorados y el mobiliario los realizaron Luis M. Feduchi, uno de los primeros arquitectos interioristas de la época, y el fabricante de muebles y decorador Luis Santamaría; ambos habían colaborado en diferentes proyectos y se habían convertido en profesionales de referencia. La película se rodó, principalmente, en platós de cine, por lo que los decorados y el mobiliario, fueron fundamentales para ambientar los espacios; de tal forma que se convirtieron en uno de sus protagonistas y se integraron, junto con la música, los diálogos y otros elementos, con el carácter dinámico, sofisticado y, al mismo tiempo, identificable y cercano que el director quiso imprimir al film.

\section{La comedia musical "El bailarín y el trabajador" de Luis Marquina}

Luis Marquina (1904-1980) tras finalizar los estudios de ingeniería en 1930, se formó como técnico de sonido de cine en los estudios alemanes Tobis de París y UFA de Berlín. La elección de Marquina se produjo en un momento en el que la industria cinematográfica en España, a partir de 1932 y tras una época de crisis, empezó a consolidarse con nuevos estudios de cine sonoro que necesitaron de medios y profesionales para su desarrollo ${ }^{2}$. Uno de los estudios fue CEA (Cinematografía Española y Americana) de Madrid, inaugurado en 1933, donde Marquina trabajó como director técnico de sonido desde su apertura hasta que pasó a ser director en 1935. La elección de Marquina por la productora no fue casual ya que su padre, el escritor Eduardo Maquina, colaboró con ella, al igual que varios inversores privados y otros dramaturgos como Jacinto Benavente, los hermanos Serafín y Joaquín Álvarez Quintero o Carlos Arniches, junto con los músicos Jacinto Guerrero y Francisco Alonso. Todos ellos se comprometieron a ceder su producción y componer obras a petición de los estudios, a la vez que fue una manera de autopromocionarse. CEA fue, en suma, la respuesta a la necesidad de desarrollar un cine propio, principalmente sonoro, para lo que contó con espacios de producción, posproducción y la capacidad de producir y distribuir sus propias películas, por lo que siguió un modelo similar al hollywoodiense ${ }^{3}$.

Durante este período Marquina se encargó de la sonorización de diferentes películas: "El agua en el suelo" (1934, Eusebio Fernández Ardavín), "La traviesa molinera" (1934, Harry D'Abbadie D’Arrast), "Vidas rotas" (1935, Eusebio Fernández Ardavín); así como de varios filmes musicales en los que intentó obtener el máximo provecho del cine sonoro, se trató de las zarzuelas "La Dolorosa" (1934, Jean Gremillon) y "Doña Francisquita” (1934, Hans Behrendt), la comedia musical "Rumbo al Cairo" (1935, Benito Perojo), el drama "La hija del penal" (1935, Eduardo García Maroto) y la parodia "Do, re, mi, fa, sol, la, si o la vida privada de un tenor" (1935, Edgar Neville) ${ }^{4}$. Estas y otras obras, podrían resumir el tipo de películas que se rodaron durante la República, centradas mayoritariamente en el entretenimiento. Así, el cine folklórico, la zarzuela filmada, algunos dramas y, sobre todo, las comedias musicales fueron las que tuvieron más éxito ${ }^{5}$. 
Tras su experiencia como técnico, en 1935 Marquina rodó su primer film "Don Quintín, el amargao", una adaptación del popular sainete de Carlos Arniches y Antonio Estremera con música de Jacinto Guerrero en la que, según la publicidad de la época, se combinaba "el gracejo madrileño con el ritmo de un film americano"6. La película fue la primera producción de la compañía Filmófono, creada en ese mismo año en Madrid por Ricardo María de Urgoiti y Luis Buñuel, que se encargó de supervisar el film ${ }^{7}$. La obra, que se rodó en los estudios CEA, tuvo un gran éxito y facilitó la siguiente película del director.

En 1936 Marquina dirigió su segunda obra "El bailarín y el trabajador", que se emitió por vez primera el 28 de abril en el Teatro Príncipe de VitoriaGasteiz y el Salón Royal de Castellón, y en fechas sucesivas en las principales ciudades de España. En Madrid la película se estrenó el 21 de mayo en el emblemático cine Capitol diseñado por los arquitectos Vicente Eced y Luis M. Feduchi, que fue inaugurado tres años antes ${ }^{8}$.

El interés de la productora por el film quedó patente en la publicidad que hizo de él como una superproducción, una obra cumbre, la mejor película española, o un filme internacional ${ }^{9}$. En palabras de Domíguez Rodiño, consejero delegado CEA, se trató de una apuesta por nuevos valores como Marquina para crear productos de calidad: "condición indispensable para afianzarnos. No hemos de regatear ni en medios ni entusiasmo para conseguirlo" ${ }^{10}$. Para ello, y a diferencia de su anterior película, el director tuvo libertad para realizar todo "con arreglo a mi criterio", incluyendo elementos técnicos, guión e intérpretes, por lo que consideró que se trataba de su primera obra ${ }^{11}$.

El filme también fue una adaptación literaria, habitual en la época debido a la carencia de guionistas, en este caso de una obra poco conocida de Jacinto Benavente Nadie sabe lo que quiere, o El bailarín y el trabajador. Humorada en tres actos (1925) ${ }^{12}$. De hecho, la publicidad destacó como reclamo "el fino espíritu satírico del más insigne de nuestros dramaturgos"13, y la crítica de la época celebró el guión y la adaptación de la obra literaria en la que, según Marquina, contó con la supervisión de Benavente ${ }^{14}$ (fig.01) $^{15}$. El propósito del director fue traducir la comedia en imágenes, adaptarla al ritmo y el dinamismo cinematográfico, para lo que introdujo modificaciones, creando algunas escenas y personajes ${ }^{16}$.

El resultado fue una comedia- musical, la única que rodó el director, en la que se narra una historia de amor entre un conocido bailarín sin dinero (Carlos Montero/ Roberto Rey) y su novia (Luisa Romagosa/ Ana María Custodio), hija de un rico empresario galletero (Carmelo Romagosa/ Pepe Isbert), que disfrutan de una vida disoluta y lujosa. El empresario, un nuevo rico hecho a sí mismo y poco refinado, no acepta a Carlos porque sospecha que quiere su patrimonio. Para desmentir estos recelos, Carlos empieza a trabajar en la sección de envases de la fábrica de galletas, pero ante su actitud relajada es trasladado al servicio de mantenimiento junto con un sencillo y honrado trabajador (Patricio/ Antonio Riquelme) que le ayuda a transformar su actitud, y a ascender en la fábrica desde el nivel más bajo, hasta convertirse en su gerente y en una persona consecuente y creativa, un "segundo yo" de Carmelo Romegosa ${ }^{17}$. Luisa no comparte la actitud más responsable de su prometido y se siente abandonada; asimismo, su padre intenta despertar sus celos al poner a trabajar juntos a Carlos y a una 
empleada (Pilar/ Antoñita Colomé), aunque finalmente y, de manera abrupta, se afianza el amor entre Luisa y Carlos.

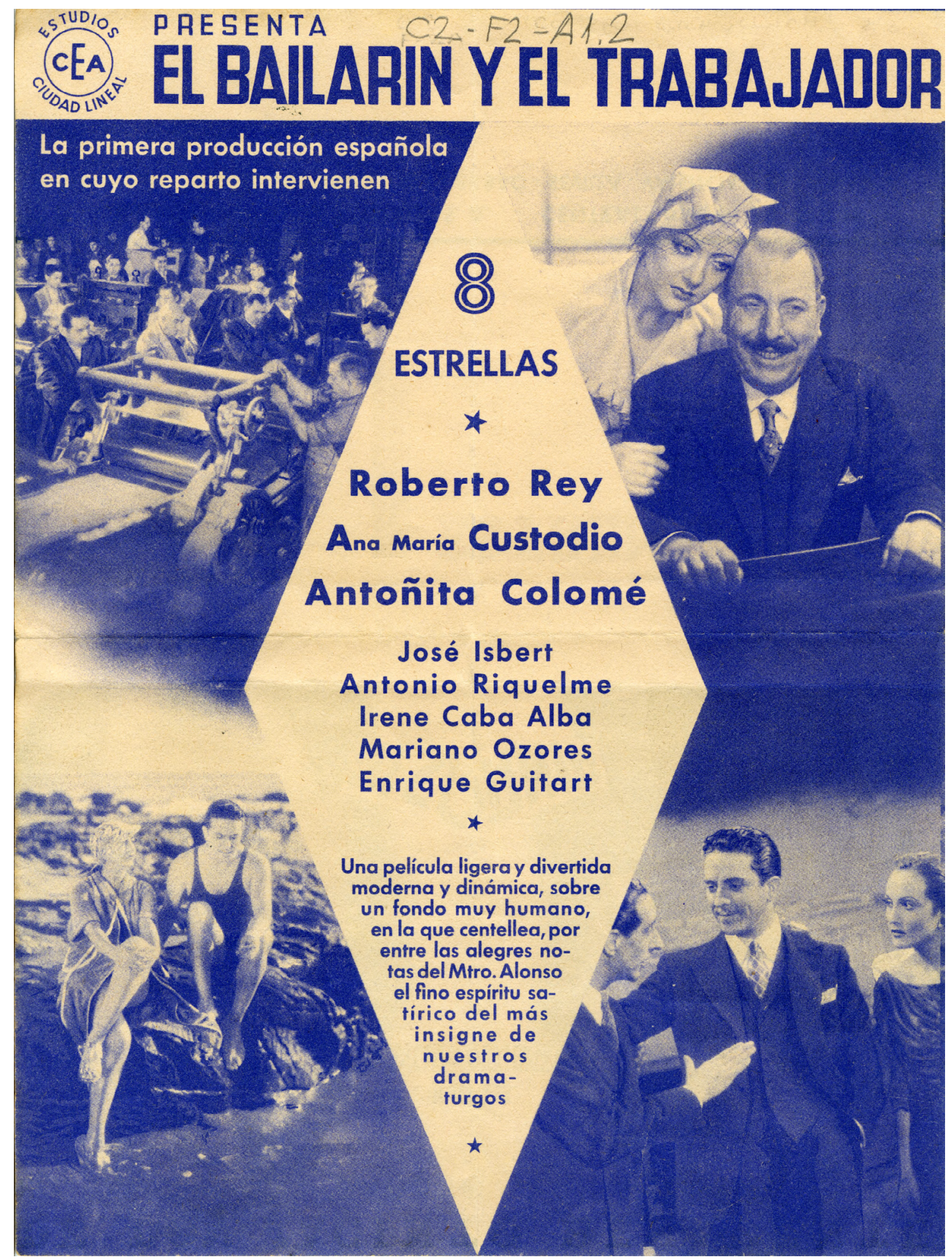

Fig.01. Publicidad de "El bailarín y el trabajador". De sus autores $\mathbb{C}$. Fuente: Filmoteca Española. 
La publicidad presentó la obra como "una película ligera y divertida, moderna y dinámica" 18 , en la que se utilizó como reclamo, además de la obra de Benavente, la música y a actores y actrices conocidos, que contribuyeron a su éxito ${ }^{19}$. Más concretamente se subrayó que se trataba de "la primera producción española en cuyo reparto intervienen ocho estrellas". Algunos de ellos llegaron a ser muy populares durante la República, tal fue el caso de los tres protagonistas: Carlos Rey, Ana María Custodio, -que había actuado en "Don Quintín, el amargao"-, y Antoñita Colomé, cuya interpretación fue la más destacada por la crítica $^{20}$. Además, los tres tenían experiencia en versiones españolas de películas de Hollywood: Rey y Custodio habían rodado varios films en Estados Unidos y Colomé para la Paramount en Joinville (París).

Otro atractivo del film, fueron "las alegres notas" 21 del maestro Francisco Alonso, ya que las bandas sonoras musicales fueron un elemento atractivo y novedoso que contribuyeron a la consolidación del cine sonoro en España ${ }^{22}$. Alonso fue un compositor muy popular por sus éxitos comerciales de zarzuelas y sus composiciones de revista musical, de cuya experiencia partió para realizar la música de sus películas ${ }^{23}$. En 1933 realizó su primera banda sonora para "El agua en el suelo" (1934, Eusebio Fernández Ardavín), que fue un éxito comercial y la primera película de los estudios CEA, de los que formaba parte. La siguiente fue "El bailarín y el trabajador", para la que creó una banda sonora que se compenetró con los intereses del director, tal como queda reflejado en la fusión y el equilibro entre el montaje rítmico y dinámico del film y la música (micky-mousing) ${ }^{24}$. Al tratarse de un musical, en algunos pasajes la música se convierte en protagonista a través de varios números como la "Marcha de las galletas", "Escena de baile en la fábrica de galletas", "Marcha al Royal Club" o "Escena de baile en el Royal Club", que denotan la influencia del cine musical hollywoodiense, que Alonso aunó con su experiencia en la revista y el sainete lírico ${ }^{25}$. Asimismo, el compositor se sirvió de recursos dramatúrgicos (como un leitmotiv en forma de vals), propios del cine norteamericano y también de las óperas de Puccini, a la vez que integró elementos de la zarzuela, el jazz y el fox. De hecho, la música fue grabada por la orquesta de jazz Moltó, dirigida por Daniel Montorio, que aparece en la película ${ }^{26}$.

La crítica destacó la calidad musical, "modernísima”27, y auguró el éxito de algunos números ${ }^{28}$. Desde la revista Cinegramas se subrayó que la obra tenía un "aire sutil de comedia cosmopolita, civilizada, inteligente, y no el burdo y rural tipismo de la zafia gitanería" ${ }^{29}$. En palabras de Guillermo de Torre el cosmopolitismo fue un "nuevo espíritu" 30 que empezó a ser habitual en diferentes manifestaciones artísticas de la época como el edificio Capitol. De igual forma, la publicidad subrayó, repetidamente, el carácter internacional y universal de la película: un "filme internacional español", "la primera película española que puede proyectarse en todas partes, porque sin dejar de ser española es universal" 31 , una obra de "empaque internacional, interesante, amena y llena de elegancia y belleza" 32, "una gran película, alegre, delicada, españolísima y, al mismo tiempo, internacional" 33 , o que "nuestro cine alcanza casi la altura de los mejores films de factura norteamericana" 34 .

De hecho, la película se centra en un ambiente urbano cosmopolita de Madrid y Biarritz en el que destaca la pareja burguesa a la que se critica, a la 
vez que se recoge y homenajea la clase trabajadora a través de la fábrica de galletas y, en todos los casos, no faltan ciertas reflexiones moralizantes. Así queda patente en el ambiente glamuroso y sofisticado de la pareja protagonista y su entorno que, -al igual que las comedias norteamericanas-, frecuentan clubs nocturnos, visten elegantes smokings y vestidos a cargo de la casa Anita $\&$ Marinette de Madrid, se desplazan a Biarritz de vacaciones donde se solazan en su casino y se muestran en bañador o en un cómodo vestuario de sport, a la vez que viven en lujosas viviendas con un mobiliario igualmente sofisticado. La modernidad tampoco es ajena al mundo del trabajo a través de la fábrica de galletas, que apenas tiene relevancia en la obra de teatro pero que en la película es una de las protagonistas, y donde se subraya el mundo de la máquina. Así se refleja en uno de los números musicales que muestra el funcionamiento de la fábrica, o en los diálogos escritos por Marquina:

"Esta fábrica es un perfecto engranaje donde las personas no son más que ruedecitas cuya misión es la de funcionar todas a una, carentes de personalidad individual y al servicio exclusivo de la exigencia de la industria" ${ }^{35}$.

La importancia del mundo de la máquina, a la que Ramón Gómez de la Serna se refirió como "maquinismo" 36 , también estuvo presente en obras como "Tiempos modernos" de Charles Chaplin que se estrenó ese mismo año, y en otros cineastas del momento ${ }^{37}$, como Ersnt Lubitsch cuya influencia reconoció Marquina $^{38}$. Asimismo, se trata de un retrato de la época que estuvo igualmente presente en propuestas literarias como la novela La Venus mecánica (1929) de José Luis Fernández, donde la trama transcurre en el Madrid de los rascacielos, los aeródromos, los automóviles frenéticos en busca de aire y campo, los music-halls, los veranos en Biarritz con excursiones y fiestas en el casino, al que se contrapone una realidad más popular ${ }^{39}$.

En la película el contrapunto a la sofisticación, elegancia y despreocupación de Carlos y Laura está en la fábrica: Carmelo, un hombre gruñón con más de veinte años de experiencia profesional que quiere enderezar a su futuro yerno para que sea como él, y también en los empleados Patricio y Pilar que se dibujan en oposición a la pareja protagonista, tanto en su actitud como en la forma de hablar, más castiza e inspirada en la zarzuela. Patricio es el encargado de la electricidad y las máquinas, y el personaje de Pilar, -que ha sido creado para el filme-, es una empleada que ha pasado de trabajar en la zona de empaquetado a hacerlo en las oficinas junto con Carlos. No obstante, y como ya hemos adelantado, la fábrica también es un lugar moderno, incluso en el uniforme de las empleadas, los letreros y los folletos de venta donde aparece una tipografía moderna que se combina con los embalajes originarios de una marca veterana.

Esta imagen de sofisticación, elegancia y lujo que predomina en todos los elementos de la película fue especialmente posible gracias a los decorados y el mobiliario que realizaron Luis M. Feduchi y Luis Santamaría, que también se compenetraron con los deseos del director ${ }^{40}$. No en vano, ya hemos anotado que la película fue rodada casi íntegramente en los estudios CEA, y contó con muy pocos exteriores, por lo que la decoración y el mobiliario fueron esenciales para recrear los espacios y ambientes requeridos. 


\section{Luis M. Feduchi, Luis Santamaría y la decoración y el mobiliario del film.}

Luis Martínez Feduchi siguió los pasos de sus tío y tutor, el arquitecto Luis Cabello Lapiedra, y en 1917 empezó a estudiar arquitectura en la escuela de Madrid donde se graduó en 1927, junto con José Manuel Aizpúrua, Joaquín Labayen, Felipe López Delgado o Manuel Martínez Chumillas, con quienes compartió el interés por la decoración de interiores que no fue habitual en la época. Además, completó su formación viajando con su tío por España, realizando apuntes de la arquitectura popular; y una vez que terminó los estudios viajó por Europa, conociendo las últimas tendencias. Todavía era un estudiante cuando, con su hermano Vicente, empezó a proyectar mobiliario para el fabricante de muebles Luis Santamaría de Madrid. Asimismo, los dos realizaron diseños para la casa Nesofksy, que contaba con un repertorio más moderno que Santamaría, a la vez que Vicente creó su propia empresa Crowner S.A., en la que colaboró Luis. Durante sus años de estudiante también tuvo la oportunidad de entender la arquitectura como una actividad integral que abarcaba los espacios interiores y el mobiliario, ello fue gracias a su colaboración en los estudios de Luis Gutiérrez Soto e Ignacio Cárdenas, con quien participó en la decoración del vestíbulo del edificio de Telefónica en Madrid ${ }^{41}$.

Feduchi empezó el ejercicio profesional independiente en 1927 como arquitecto escolar, donde mostró su interés por lo vernáculo, igualmente presente en algunas publicaciones posteriores ${ }^{42}$. Prosiguió con la restauración y rehabilitación del castillo de Oropesa para convertirlo en el primer Parador de Turismo (1929-1931), incluyendo el mobiliario inspirado en tipos históricos y populares, a los que se aproximó desde la actualización, marcando así una de las características de sus diseños ${ }^{43}$. De igual forma, se encargó de la construcción de varias residencias y locales comerciales modernos ${ }^{44}$.

En 1930 con Vicente Eced, amigo y vecino suyo desde la infancia y compañero de carrera, proyectó el conocido edificio Capitol, en la Gran Vía de Madrid, que fue construido entre 1931 y 1933 tras ganar el concurso que para tal fin organizó Enrique Carrión ${ }^{45}$. La obra fue calificada como "el faro del Madrid nuevo y cosmopolita"46, y en ella podemos encontrar referencias a la arquitectura de Erich Mendelsohn, el mundo de la máquina y los rascacielos americanos. Se trató de un edificio que albergó un complejo programa de hotel, apartamentos, oficinas, cafetería, salón de espectáculos y cine que, recordemos, acogió el estreno en Madrid de "El bailarín y el trabajador"47. Eced y Feduchi, motivados por el proyecto que tenían que llevar a cabo, viajaron a Francia y Alemania para estudiar los cines que se estaban construyendo; y Feduchi, junto con Francisco Benito Delgado, viajó a Londres, Ámsterdam y Hamburgo para informarse sobre sistemas de iluminación que caracterizaron al edificio y a la Gran Vía de la capital $^{48}$. Según la revista Cinegramas el nuevo edificio supuso "un jalón en la historia del nuevo Madrid" y un:

“(...) paso gigantesco en su camino de gran ciudad del mundo. Fue entonces cuando nuestra ciudad flirteó con Cosmópolis y cuando las luces de Nueva York se encendieron sobre la villa del piropo y el mantón. Sobre el 
mar abigarrado de la Gran Vía (...) avanzaba gallardamente, como un penacho de la vida suntuosa del mundo, la nave magnífica del nuevo edificio. Madrid adquiría de golpe un admirable rango de ciudad internacional" ${ }^{49}$.

También se añadió que el edificio marcaba una renovación propia de "las audacias de hoy", lo que le convertían en:

“(...) faro de la vida nueva de Madrid, gallardete de cemento y de luces, a cuya sombra vive y pasa la parte más bella y más actual de la capital española (...) un trasatlántico que traía a nuestra vida la visión espléndida de los lujosos ambientes lejanos, de las ciudades que son antorcha del mundo. Y desde aquel día (...) Madrid se esforzó en adquirir un nuevo tono (...) un estilo nuevo de elegancia y alegría"50.

"De este Madrid alegre y brillante puede considerarse símbolo aquel edificio del Capitol, expresión máxima de la nueva alegría y la nueva elegancia de la ciudad ${ }^{51}$.

A ello contribuyó el mobiliario del edificio que Feduchi diseñó en función de las necesidades de cada espacio, para lo que trabajó con las empresas Lledó y Rolaco-Mac para realizar propuestas más novedosas de inspiración internacional, y con Santamaría y Crowner para otras más tradicionales ${ }^{52}$ (fig.02). El trabajo de Rolaco-Mac supuso el mayor encargo que la empresa llevó a cabo hasta entonces y una carta de presentación de una firma que fue pionera en la fabricación de muebles de acero curvado. A partir de entonces se estableció una relación entre Feduchi y la firma de mobiliario que propició que, durante un breve periodo del año 1933, el arquitecto fuera el asesor artístico de la empresa. Desde Rolaco influyó para que se importaran muebles de Marcel Breuer y que se introdujeran diseños elaborados por él y otros profesionales ${ }^{53}$.

En 1934 interrumpió su colaboración con Rolaco, por lo que la relación con Santamaría, que no se había detenido, fue más activa. En aquella época Santamaría se consolidó como un referente en la decoración de interiores en Madrid tal y como lo reflejan las revistas de decoración Viviendas y Nuevas Formas $^{54}$. En 1934 Nuevas Formas haciendo referencia a los interiores de la firma apuntaba que:

“(...) ahora cierta parte del público, cansado de la inexpresiva y rígida solución del mueble funcional, parece aceptar complacida las modernas estilizaciones románticas. (...) Son estas formas dirigidas por líneas más orgánicas y adaptadas al modelo del cuerpo humano; más acogedoras, más amables. Invitan al reposo y a una vida de relación menos áspera"55.

Seguidamente, en 1936 Santamaría y Feduchi crearon la "Sociedad Santamaría y Feduchi de Muebles y Decoración”. Paralelamente, el arquitecto prosiguió con la construcción, rehabilitación y decoración de otros proyectos arquitectónicos ${ }^{56}$, y a partir de 1935 también en el ámbito del cine y el teatro, por lo que siguió el camino de otros arquitectos del momento, como Robert Mallet-Stevens. 


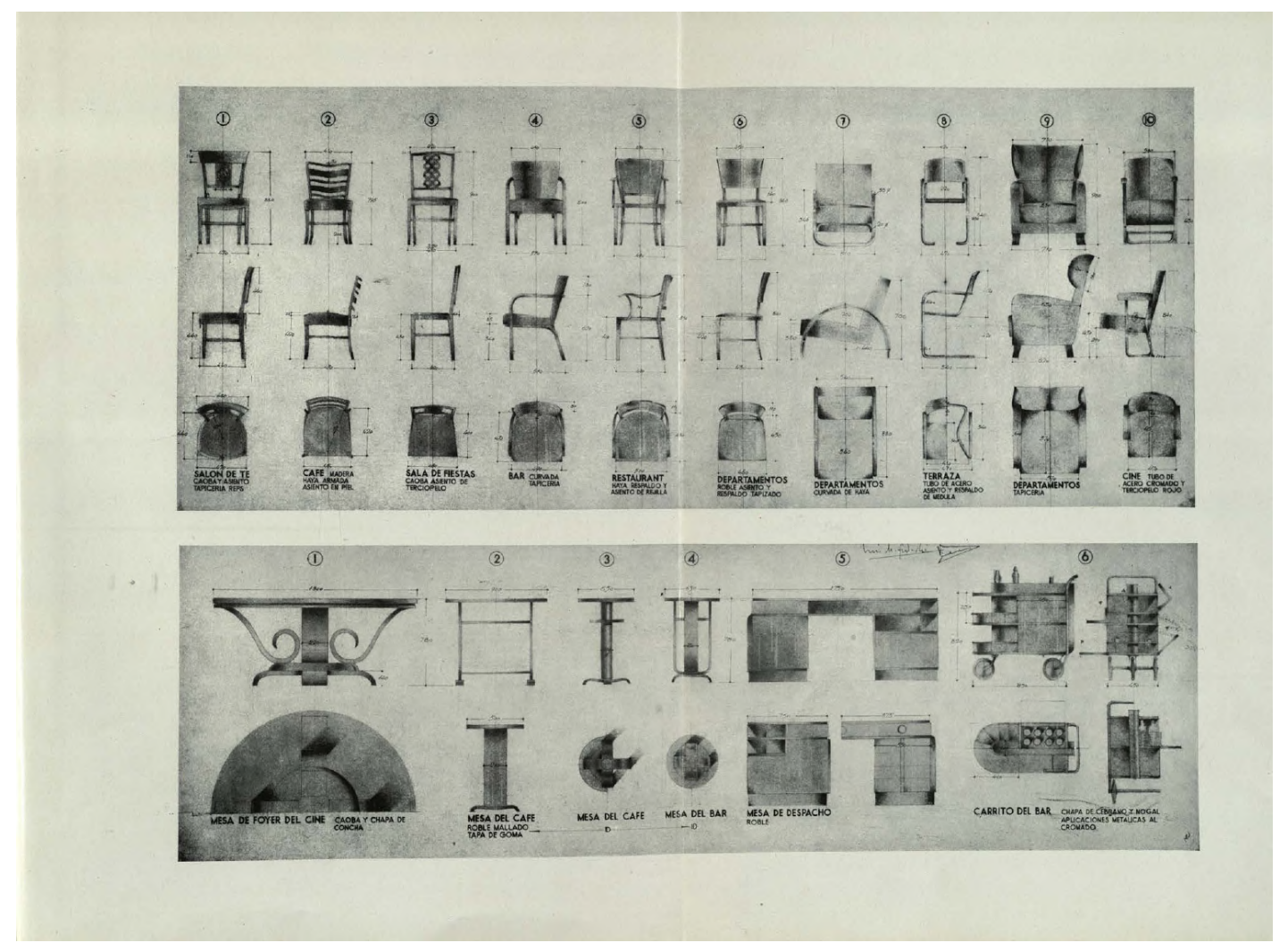

Fig.02. Mobiliario para el edificio Capitol. Fuente: revista Arquitectura, enero-febrero 1935.

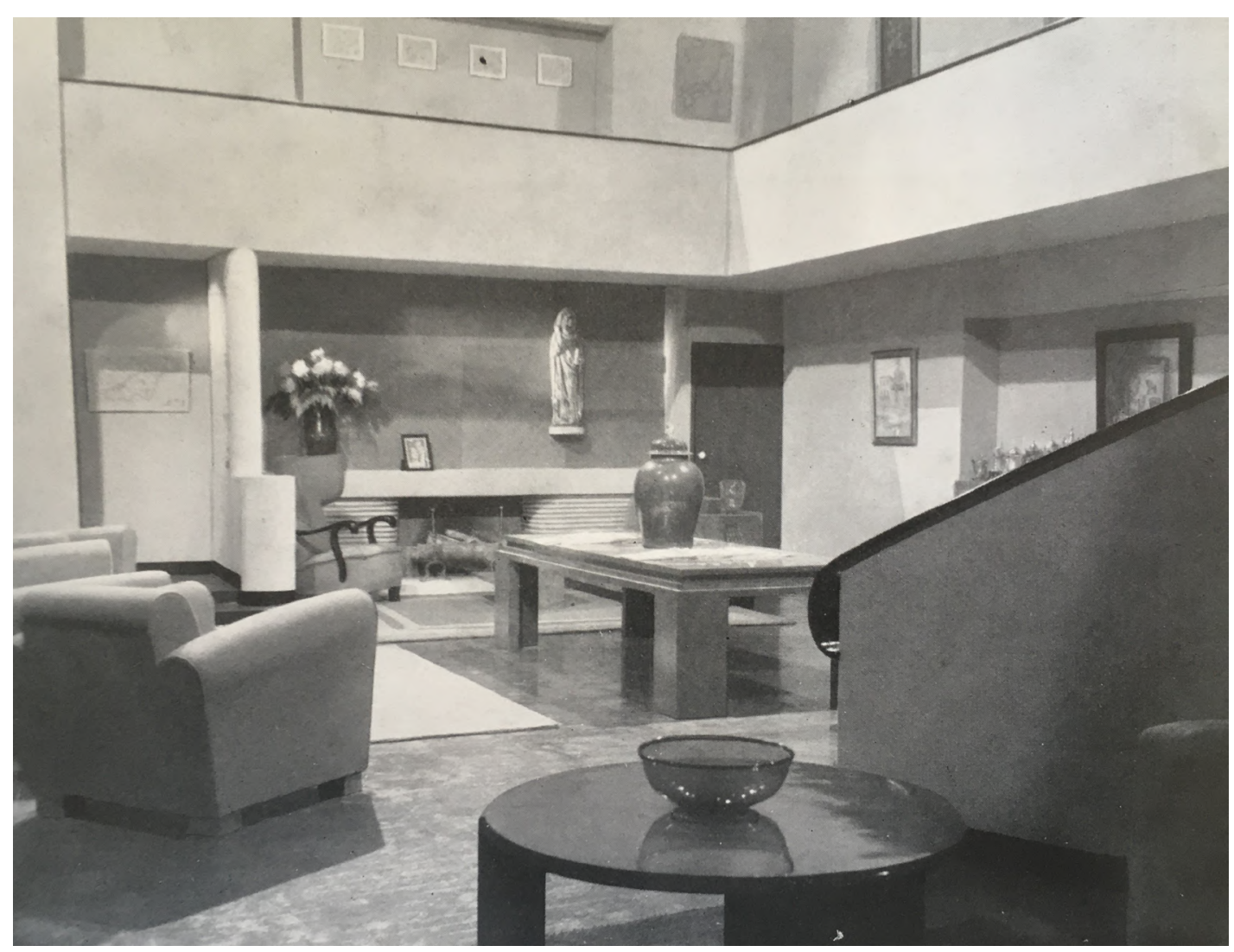

Fig.03. Decorados para un film. Fuente: revista Nuevas Formas 1935. 
Hemos de tener en cuenta que durante la República el sector de la construcción estuvo en crisis debido a la situación económica de aquellos años, mientras que el sector cinematográfico experimentó un gran desarrollo, al que Feduchi se sumó realizando el decorado de películas, para lo que contó con la colaboración de Santamaría en el mobiliario y Benito Delgado en la iluminación ${ }^{57}$. Más concretamente en 1935 realizó los decorados de dos filmes dirigidos por Eusebio Fernández Ardavín: "Vidas rotas", donde Marquina trabajó como responsable de sonido, y "La bien pagada", producida por CEA. Algunos de los decorados fueron publicados en Nuevas Formas en el mismo año ${ }^{58}$ (fig.03). En consecuencia, en 1936 Feduchi y Santamaría, que llevaban una larga trayectoria que había dado lugar a la creación de una firma de decoración conjunta, tenían experiencia en el cine, y también en los estudios CEA; a la vez que eran conocidos por sus propuestas de mobiliario versátil, cosmopolita y moderno, -concretados de manera conocida en el edificio Capitol, que se adecuaban a las necesidades de "El bailarín y el trabajador"-, eran los candidatos perfectos para encargarse de la decoración y el mobiliario de la película.

Para elaborar los decorados de los espacios interiores del film, Feduchi y Santamaría contaron con la colaboración de José María Torres, -que también lo hizo en la anterior película de Marquina-, y la del escenógrafo José Redondela (José González Gordo) ${ }^{59}$. El presupuesto del film fue de 480.000 pesetas $^{60}$, por lo que estaba lejos de la gran producción que se publicitó, ya que fue inferior a la comedia musical "La verbena de la Paloma" de Benito Perojo del año anterior, y totalmente ajeno a los dos millones de dólares de "Tiempos modernos" de Chaplin. Esta situación posiblemente determinó que la película se rodara, casi en su totalidad, en espacios interiores. En palabras de Marquina: "No hay muchos exteriores en 'El bailarín y el trabajador" 61.

La película trascurre en las salas de fiestas de un casino en Biarritz y un hotel en Madrid (Royal Club), viviendas particulares, la fábrica de galletas, los asientos de primera clase de un tren, una playa de Biarritz, y las calles de una ciudad filmadas durante la noche con luces de neón que aparecen al final de la película. Los únicos escenarios naturales fueron: la costa levantina ${ }^{62}$, la fábrica galletas "La Fortuna" de Madrid ${ }^{63}$ y, presumiblemente, la Gran Vía de Madrid durante la noche. El resto de la película se grabó en CEA, que contaba con tres estudios de rodaje de diferentes dimensiones: 966, 672 y $400 \mathrm{~m} 2^{64}$. Por lo que la decoración y el mobiliario, como hemos anotado, fueron esenciales para ambientar los espacios de la película. La revista Cine Español subrayó "la escenografía, de riqueza no acostumbrada, con decorados suntuosos y llenos de realidad fotogénica" "65, a lo que Cinegramas añadió que Feduchi y Santamaría eran "dos muchachos jóvenes, con una afición sin límites y una idea muy personal y muy acertada de lo que ha de ser la escenografía en el cinema"66.

Uno de los espacios más destacados de la película es un salón de fiestas, primero en Biarritz, -presumiblemente su casino aunque sin referencia alguna a su arquitectura deco y su decoración interior-, y más tarde en el Royal Club ${ }^{67}$. Se trata del mismo espacio con una gran pista de baile circular, pero con un decorado y un mobiliario ligeramente diferentes. En el de Biarritz, donde comienza la película, nos encontramos ante un espacio abierto, a modo de terraza ${ }^{68}$ con sillas de médula, con el fin de concretar el ambiente estival en el que se sitúa 
la escena (fig.04). Más concretamente, se decantaron por sillas diseñadas por José Manuel Aizpúrua y Joaquín Labayen; así como varios diseños de Feduchi y otros, posiblemente del mismo arquitecto, inspirados en modelos de Thonet.

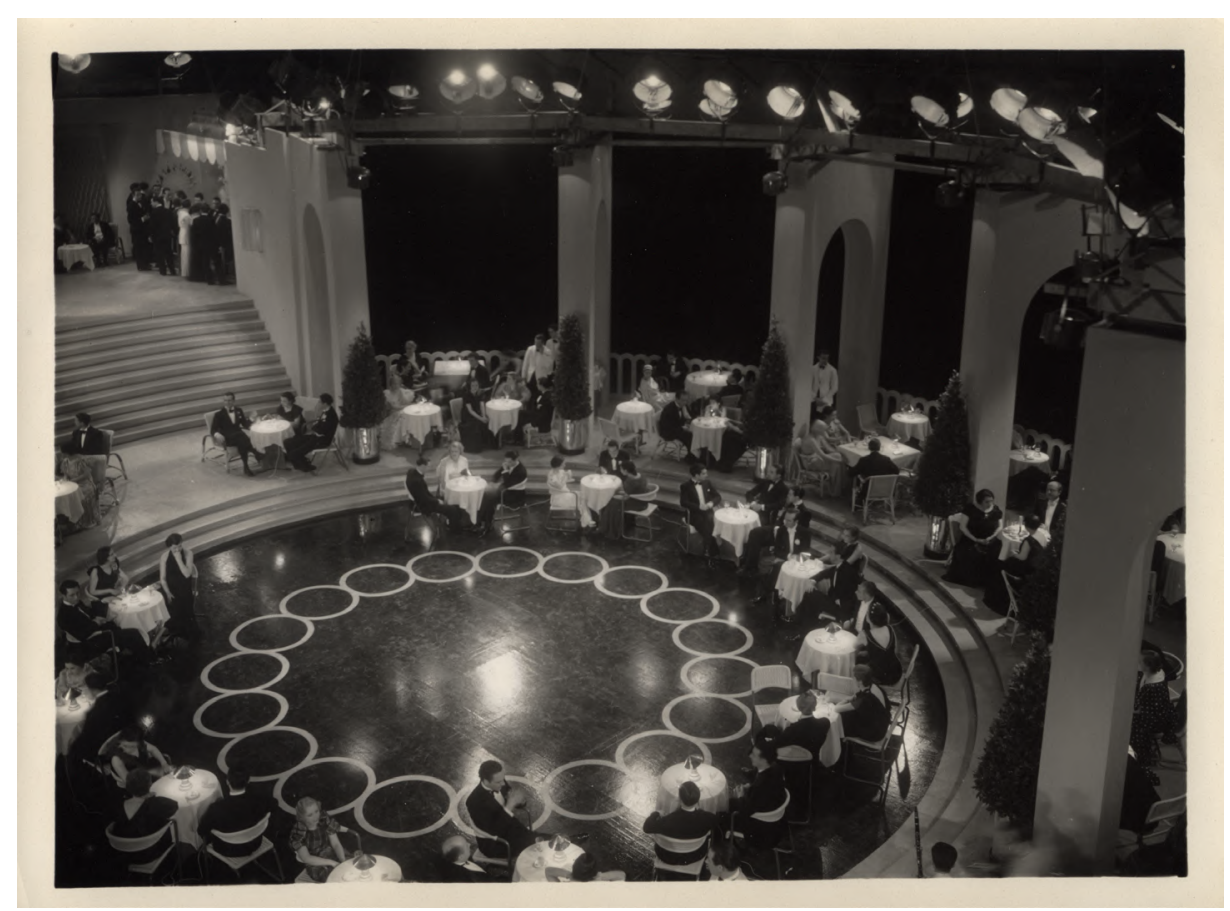

Fig.04. Salón de baile en Biarritz. F-327-8. De Filmoteca Española C. Fuente: Filmoteca Española.

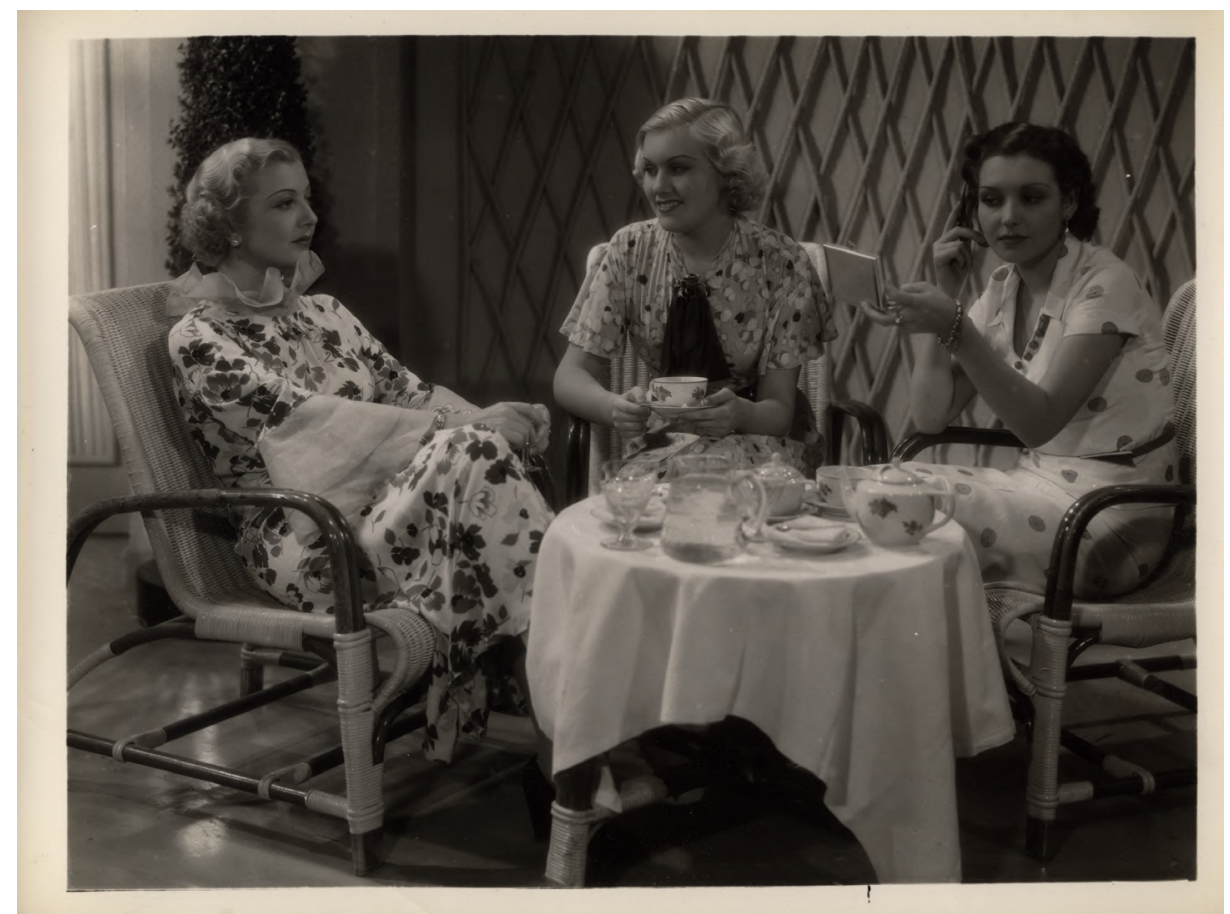

Fig.05. Terraza en Biarritz. F-327-17. De Filmoteca Española (C. Fuente: Filmoteca Española. 


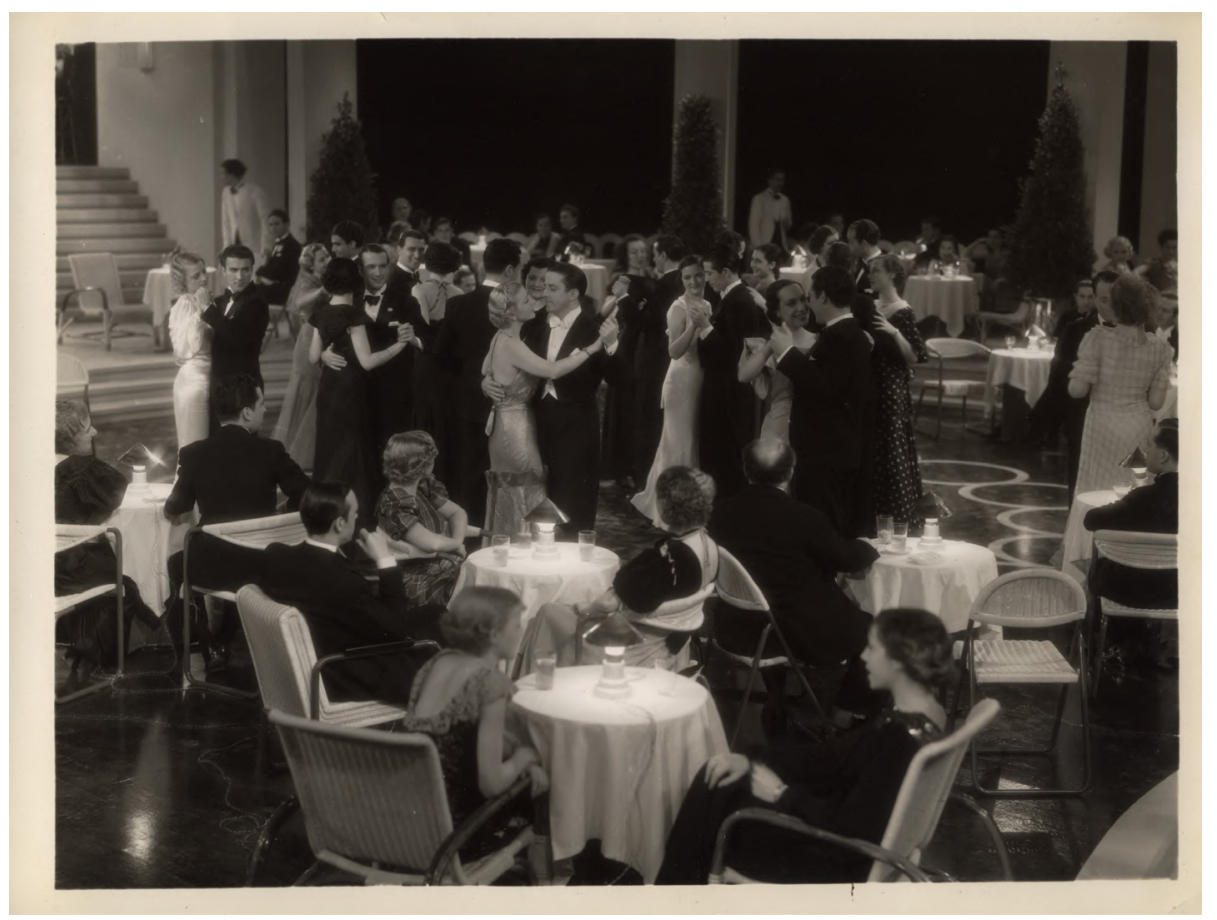

Fig.06. Salón de baile en Biarritz. F-327-38. De Filmoteca Española C. Fuente: Filmoteca Española.

De Aizpurúa y Labayen se utilizó, tanto en el salón de baile como en una escena de terraza diurna posterior, la silla GATEPAC de madera y médula que presentaron en el verano de 1932 (fig.05 y fig.06). La silla formaba parte del mobiliario del grupo GATEPAC, al que pertenecían los dos arquitectos junto con otros colegas de Barcelona que, a partir de 1931, empezaron a diseñar un moblaje económico estándar. El uso de la madera y la médula coincidió con la nueva orientación de la arquitectura racionalista de los miembros del grupo que, siguiendo a otros colegas europeos y la tradición local, entendieron la modernidad a partir de la tradición arquitectónica popular mediterránea y se alejaron de los armazones de tubo de acero y referencias maquinistas de propuestas anteriores, que Feduchi calificó como frías, rígidas y de aspecto sanatorial ${ }^{69}$. Más concretamente la silla siguió el modelo 512 de Erick Dieckmann de 1931 que publicó Viviendas junto con otras propuestas de "muebles de verano" ". La casa Dámaso Azcue de Azpeitia (Gipuzkoa), fundada en 1913 y especializada en muebles de madera, médula, junco y mimbre, se encargó de fabricar la silla y otros diseños de los mismos arquitectos que se comercializaron en Madrid, Sevilla y sus sucursales en Barcelona: en la Rambla Flores y en la sede del GATEPAC en el Paseo de Gracia ${ }^{71}$. Además, la silla de Aizpúrua y Labayen se expuso en la IV Feria Internacional de Muestras de Barcelona que tuvo lugar en julio de 1933, y se publicó en los programas de mano de la programación de invierno del Liceu de 1934/1935. Asimismo, apareció en el número 19 de la revista $A C$ del GATEPAC de 1935, dedicado a la decoración interior, como parte del mobiliario de las casas para el fin de semana en el Garraf (1934) de Josep Lluís Sert y Josep Torres Clavé en las que habían asumido una arquitectura acorde con la tradición mediterránea; a la vez que amuebló el estudio de 
otro arquitecto del grupo, Germán Rodríguez Arias, que publicó Nuevas Formas en $1935^{72}$.

No obstante, en los proyectos de aquellos años se siguió utilizando mobiliario de armazón metálico, y así sucedió también en la película con diferentes piezas inspiradas en la casa Thonet. Cabría recordar que la firma vienesa fue uno de los principales referentes de muebles modernos en España, contó con distribuidores en Madrid, Barcelona, Valencia y Sevilla, se publicitó en las principales revistas profesionales y estuvo presente en diferentes proyectos de la época. En el film se utilizaron varias sillas de estructura de acero y asiento y respaldo de médula, materiales que habían utilizado Lilly Reich, Ludwig Mies y Mart Stam. Una de ellas se podría haber inspirado en el modelo SS33 de Anton Lorenz ${ }^{73}$, de la que se había sustituido el material acolchado por médula, se había invertido la forma del respaldo, y se había sustituido el sistema cantiléver por otro de dos cuerpos tubulares independientes que evitaba la estructura batiente. Otra silla siguió el modelo B61 de 1928, de la que respetó su estructura metálica y se sustituyó la madera del respaldo y el asiento por médula ${ }^{74}$. Las dos propuestas estaban en consonancia con el diseño de silla de tubo con asiento y respaldo de médula que Feduchi diseñó para la terraza del edificio Capitol ${ }^{75}$ (fig.02, silla 8). De igual forma, Labayen y Aizpúrua realizaron un diseño con los mismos materiales, la silla Sacha (1931), para la terraza de la pastelería y salón de degustación del mismo nombre en San Sebastián ${ }^{76}$. Por lo que la elección de los materiales para la terraza del casino siguió los convencionalismos de la época. Otro elemento novedoso de la sala de fiestas son las lámparas de las mesas, que presentan un diseño sencillo y moderno, con un cuerpo geométrico que se cubre con una tulipa cónica de pequeño tamaño, similar a otras propuestas contemporáneas.

Gracias a las referencias en la revista Cinegramas durante el rodaje en marzo de 1936, conocemos cómo se llevó a cabo la construcción, todavía por concluir, del decorado de Royal Club donde tiene lugar la última escena del film (fig.07 y fig.08). En el plató más grande de los estudios se montó el decorado del hall y la sala de fiestas de un "hotel elegante":

“(...) suntuoso, de buen gusto. Un armazón de columnas, que se suponen robustas y no son más que de un armazón de yeso, aparentan sostener un techo que no existe, y por una doble escalera de falso mármol - madera forrada de papel pintado - se asciende al hall. A primera vista parece magnífico; pero uno de los lados está en vano, y por él vemos el tablado que lo sostiene, lleno de maderas entrecruzadas y pies derechos"77.

En este caso los decoradores optaron por un espacio interior completamente cerrado, en el que destacaron barandillas con motivos curvados y columnas salomónicas blancas, que también se utilizaron en la película "Raza" (1941, José Luis Sáenz de Heredia), de cuyos decorados se encargó Feduchi78. En el Royal Club se prescindieron de las sillas del anterior salón de espectáculos, y se adoptaron otras más tradicionales de madera tapizadas, así como lámparas de mayores dimensiones con tulipas enteladas.

Entre tanto, en el plató pequeño se rodó otra escena. "El decorado es la sección de empaquetado de una fábrica de galletas. A un lado y a otro, dos 
mostradores largos" 79 en los que trabajan mujeres vestidas de manera sofisticada, dentro de un espacio aséptico que imitaba una estructura de hormigón armado con grandes ventanales ${ }^{80}$. Por otra parte, en las oficinas de la fábrica, se utilizó un mobiliario diverso, en el que se mezclaron elementos más convencionales con mobiliario de armazón metálico, algunos de ellos presentes en el edificio Capitol ${ }^{81}$ (fig.02, silla 4).

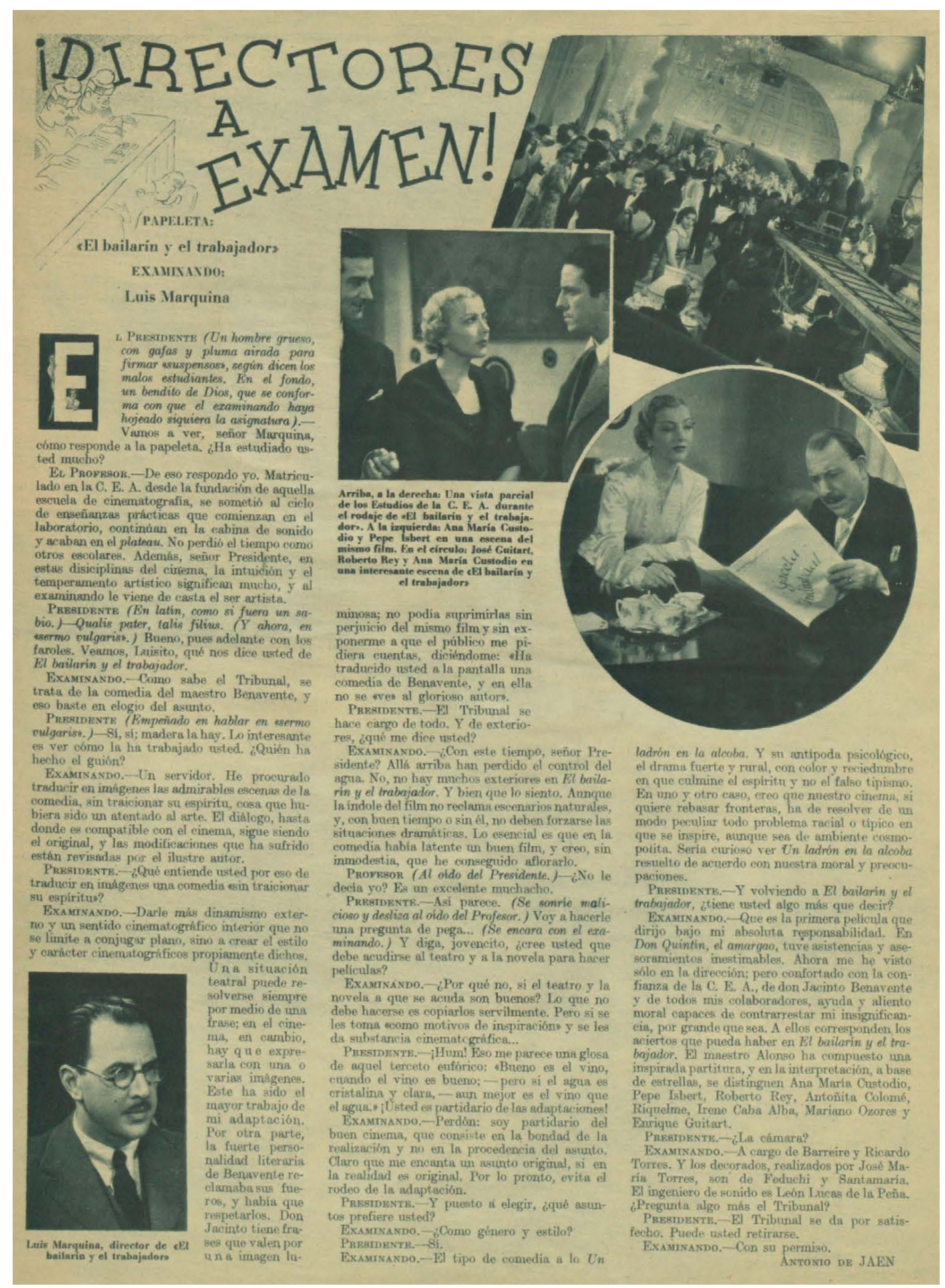

Fig.07. Fotografías del rodaje. Fuente: revista Cinegramas, 17 de mayo de 1936. 


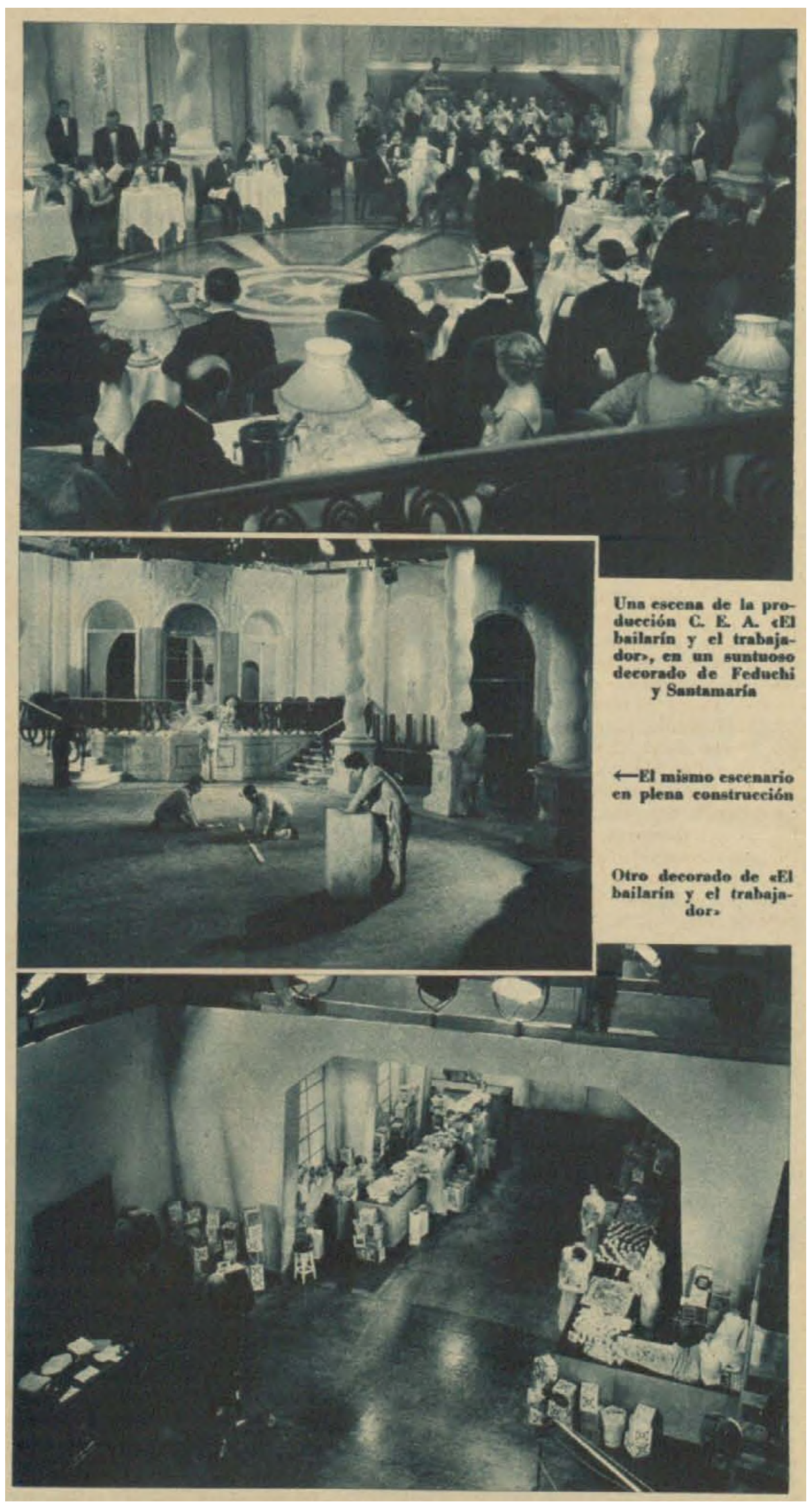

Fig.08. Fotografías del rodaje. Fuente: revista Cinegramas, 15 de marzo de 1936. 
Además de espacios de ocio y trabajo, la película presenta varios espacios domésticos: la casa de veraneo de Biarritz y la casa de la familia Romegosa, aunque también se sugieren, sin referencia alguna, las viviendas de Pilar y Patricio. Las viviendas de Biarritz y Madrid son lugares exclusivos y lujosos, aunque la primera es más moderna que la segunda.

La vivienda de la familia Romegosa muestra un ambiente sofisticado que se concreta en un salón y dos dormitorios. El espacio del salón se articula en base a pilastras estriadas, y se completa con mobiliario de madera, en algunos casos con detalles dorados, y en otros con líneas curvas: en una cómoda ${ }^{82}$, o en sofás y sillones con brazos vueltos y abiertos, muy característicos de los diseños de Feduchi y Santamaría (fig.09). Los dorados están inspirados en muebles hispanos de época fernandina, y las líneas curvas de los sofás en modelos isabelinos y también neoclásicos que Feduchi recogió en sus obras Antología de la silla española, Historia del mueble o El mueble español, y reutilizó en la película "Correo de Indias" (1942, Edgar Neville) ${ }^{83}$ (fig.10). No en vano, Feduchi tenía un detallado conocimiento de la historia del mueble y así quedó patente en las numerosas obras que publicó a partir de los años cuarenta. En 1936 Nuevas Formas apuntó que el arquitecto conjugaba "sabiamente con los gustos modernos estilos tan españoles como el fernandino o el isabelino" ${ }^{44}$, esto es, que era capaz de reinterpretar el pasado a partir de la depuración y la simplificación.

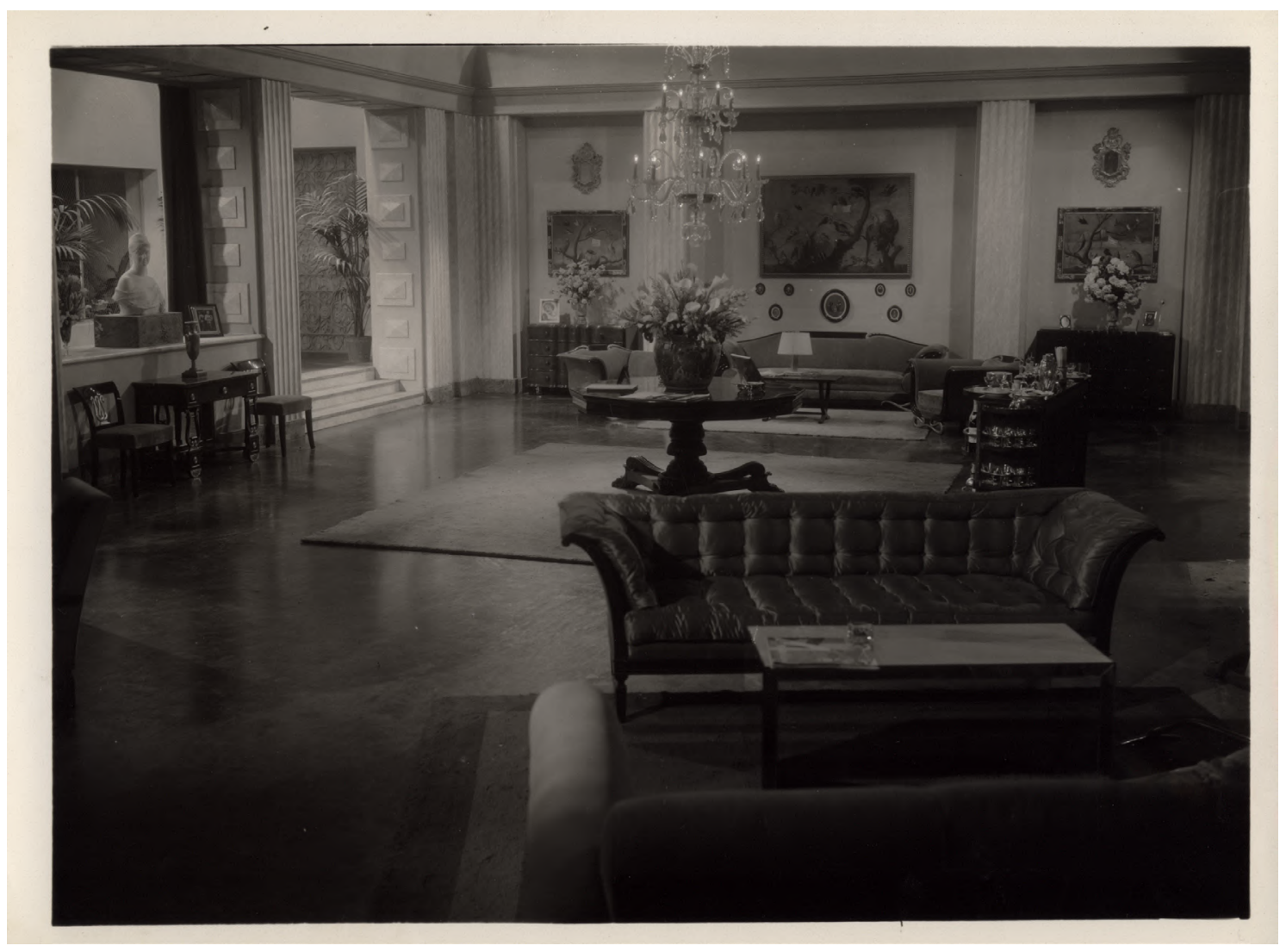

Fig.09. Salón de una vivienda. F-327-12. De Filmoteca Española (.

Fuente: Filmoteca Española. 


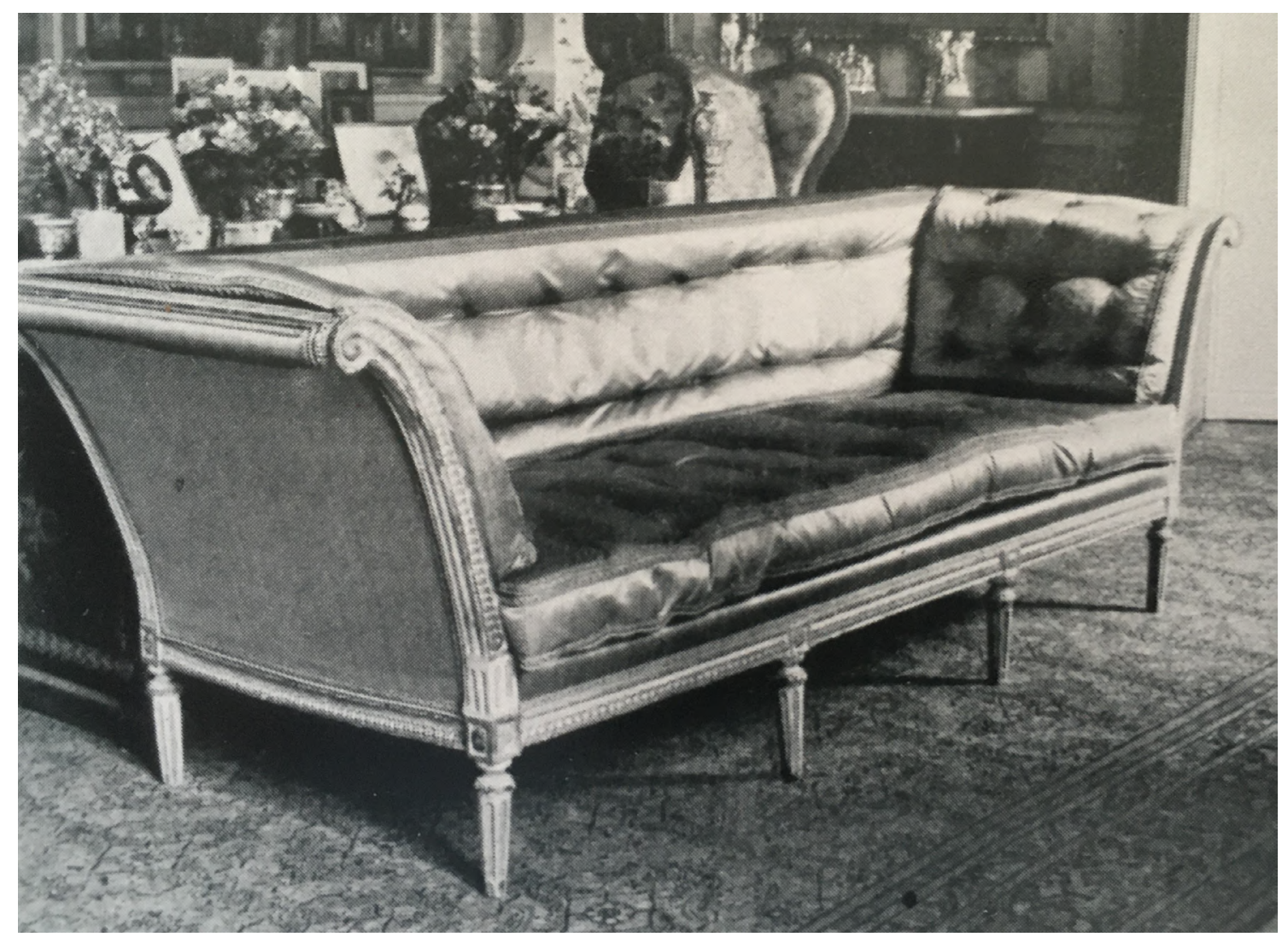

Fig.10. Sofá de línea Luis XVI del Palacio de Liria de Madrid.

En el salón también podemos apreciar mesas de diferentes características, como una consola de patas con liras, acompañada de dos sillas, que se publicó en número de Nuevas Formas antes citado como ejemplo fernandino ${ }^{85}$. Por otra parte, la mesa central es una estructura geométrica de gran volumen, similar a los modelos del Museo Romántico de Madrid que recoge en su libro Historia del mueble ${ }^{86}$; mientras que las mesas que acompañan a los sofás son más livianas y de factura más moderna. Sin embargo, en el carrito de bar utiliza una propuesta más conservadora y no la conocida que realizó para el edificio Capitol. La decoración se completa con alfombras lisas, un busto femenino, lámparas de araña, jarrones con flores, retratos, espejos rococós y cuadros con conciertos de aves muy característicos en la pintura flamenca barroca de Frans Snyders, Jan Fyt o Paul de Vos, que se presentan como un guiño a la importancia de la música en el film, y que se repite en otros decorados.

En suma, el arquitecto siguió su premisa de no utilizar una unidad de estilo, sino de encajar hábilmente conjuntos o grupos heterogéneos con el fin de presentar la personalidad de quien lo habita. Igualmente, en los elementos del salón adoptó una colocación cuidada con el fin de combinar diferentes perspectivas, que hacen ganar al espacio en ambiente y volumen que, años más tarde, Feduchi reconoció como una influencia del cine en la decoración ${ }^{87}$.

Respecto a los dormitorios, presentan un mobiliario más uniforme. El de Laura es un espacio glamuroso, casi de fantasía, acorde con su personalidad, con las paredes con decoraciones de escayola de formas vegetales, líneas curvas, 
cordones y flechas (fig.11). El mobiliario es acolchado en los pies y el amplio cabecero de la cama, así como en una banqueta auxiliar con flecos ${ }^{88}$. Las mesillas de madera muestran tiradores decorativos y un diseño curvado en los cajones con líneas sinuosas en la base, que se podrían haber inspirado en muebles estilo Luis XV que también estudió en sus publicaciones, como si de una versión actualizada de ellos se tratase. La decoración se completa con alfombras de pelo largo, una estatua de porcelana, una lámpara de araña y lámparas de mesillas con tulipas con flecos sobre un pie y una base de líneas rectas con estrías que nos podría recordar al art deco.

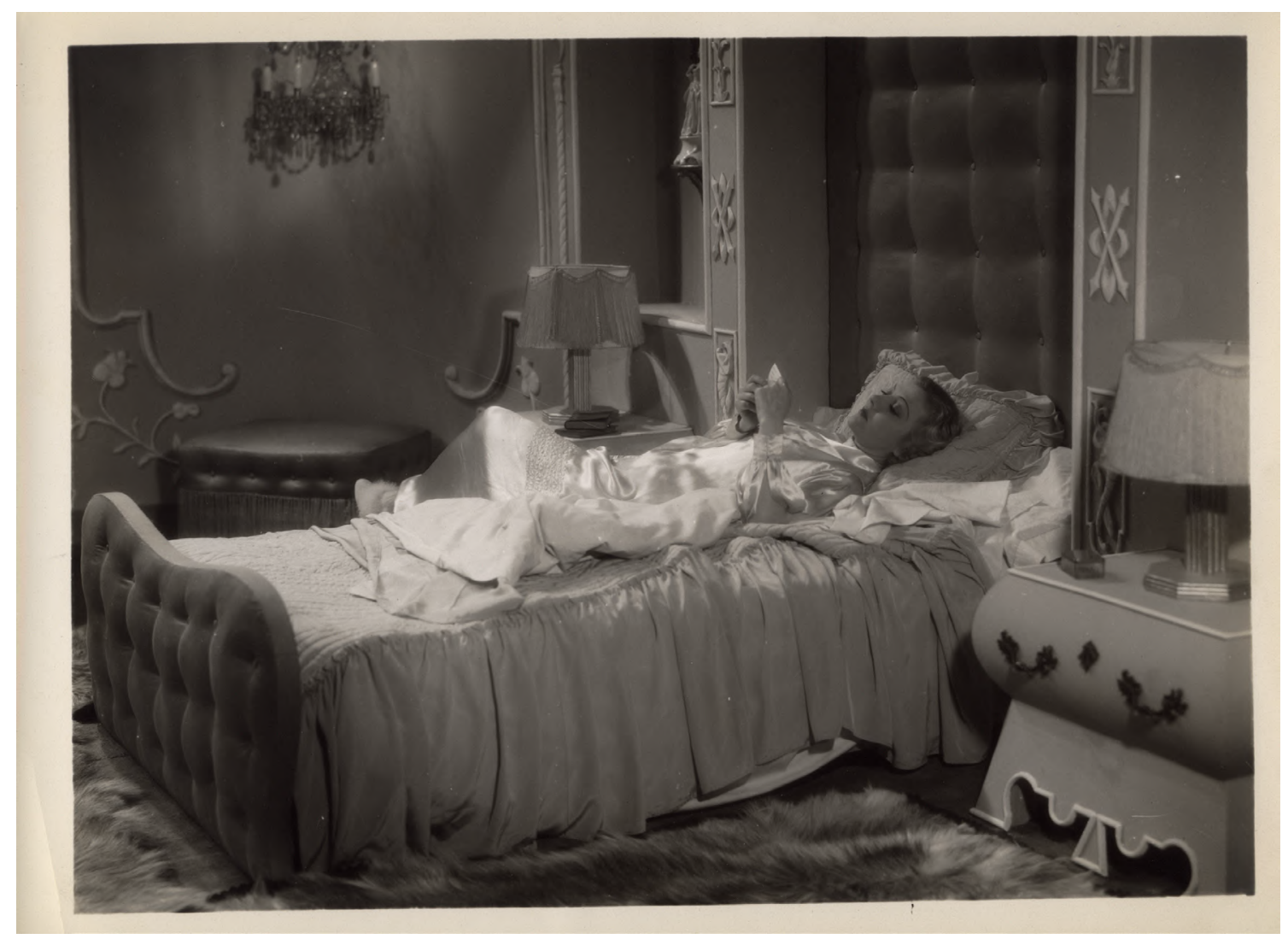

Fig.11 Dormitorio de una vivienda. F-327-36. De Filmoteca Española C.

Fuente: Filmoteca Española.

El otro dormitorio, posiblemente del padre, Carmelo, es más moderno, alejado de la tradicionalidad del salón y del carácter fantasioso de la habitación de Laura (fig.12). Las paredes aparecen recubiertas de paneles en relieve y cuadros también de pájaros. En la habitación se diferencia una zona de tocador y otra de estar en torno a un bay window con macetas y cortinas; en esta última se concreta un rincón de estar delimitado por una alfombra sencilla de bandas horizontales, sobre la que aparecen diferentes piezas de mobiliario de tono claro en la que se sigue una línea moderna sencilla. Se trata de sillones de madera con rejilla en el respaldo y cojines, alrededor de una mesa de madera ${ }^{89}$. Mientras que en la otra zona aparecen muebles que siguen la misma línea: un 
tocador plegable y dos sillas también de madera y respaldo de rejilla, que en todos los casos nos remite a los diseños de líneas más puras de los decoradores de estos años. Por lo que al igual que en otros proyectos anteriores, Feduchi y Santamaría optaron por una decoración ecléctica que se ajustó al carácter que quisieron imprimir a cada uno de los espacios, que estuvo en consonancia con los personajes y con el carácter de la comedia.

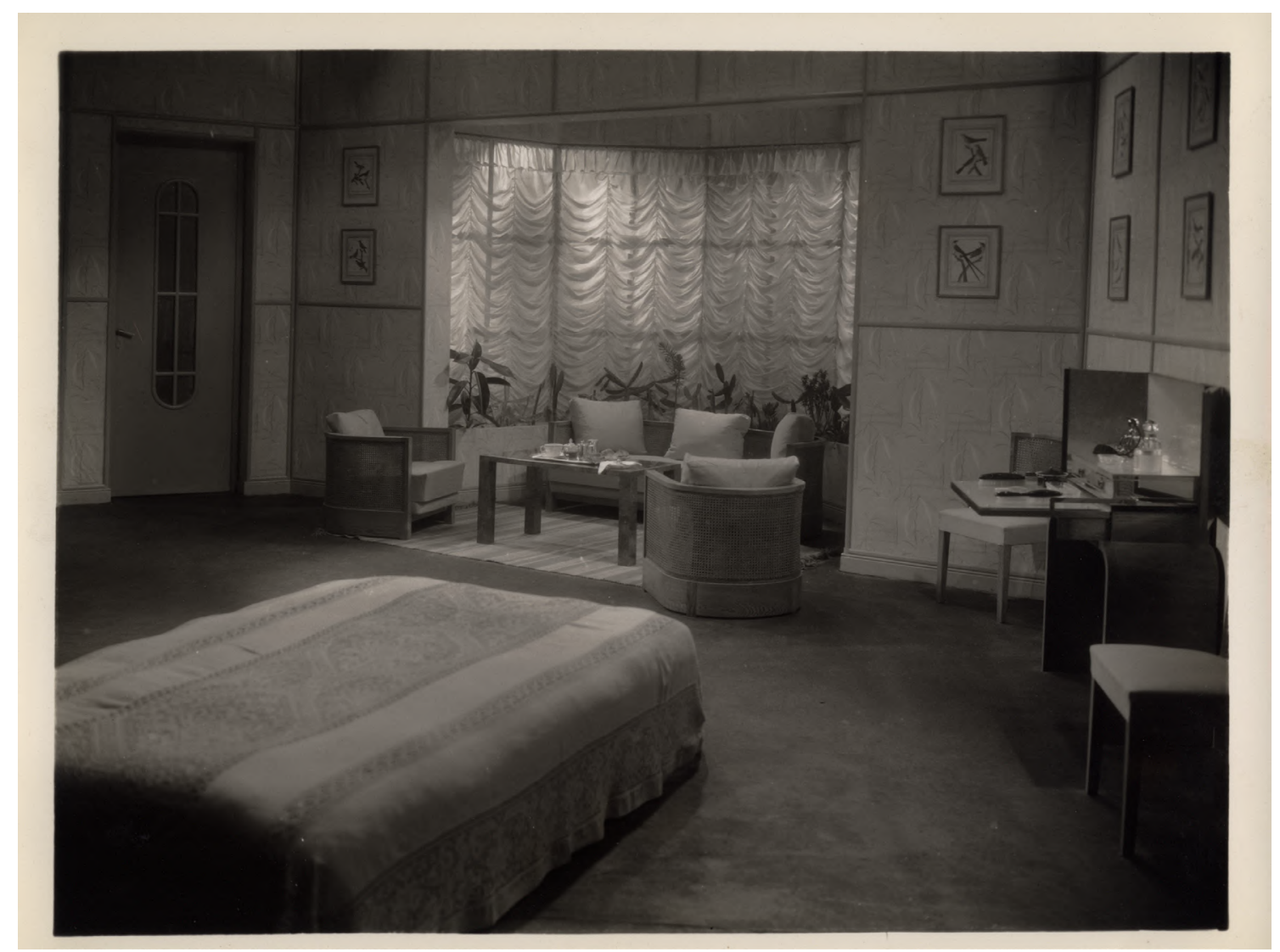

Fig.12. Dormitorio de una vivienda. F-327-13. De Filmoteca Española (C.

Fuente: Filmoteca Española.

\section{Hacia una obra de arte total}

"El bailarín y el trabajador" destaca por la ambición y vocación de Luis Marquina por crear una comedia-musical cosmopolita y universal dentro del incipiente desarrollo del cine sonoro en España, que produjo CEA en una apuesta por afianzarse en el nuevo y competitivo mercado cinematográfico. En la película el director fue capaz de reunir y aunar en un objetivo común de diversión y entretenimiento el trabajo de algunos de los profesionales más relevantes de la literatura, la música, la interpretación y la decoración de interiores de la época, dando lugar a uno de los films más interesantes de la República.

Para ello el joven e inexperto director aunó varias fórmulas de éxito en las que combinó la universalidad del cine de Hollywood, con la tradición local de las comedias teatrales y el teatro lírico. A ello sumó la interpretación de conocidas 
estrellas del cine español que tenían experiencia en el cine norteamericano y también en otros espectáculos de gran éxito de público. Asimismo, la aportación de Luis M. Feduchi y Luis Santamaría fue decisiva, ya que los decorados y el mobiliario fueron indispensables para ambientar los espacios, y contribuyeron a definir las situaciones y caracterizar los personajes, a la vez que fue una manera de promocionarse.

Se trató de una obra dinámica de vocación popular y comercial ${ }^{90}$, que en la época se calificó como una "obra maestra", "otro de los films cumbres de la cinematografía nacional"91, "uno de los contados films españoles con preocupaciones técnicas y estéticas"92, que el propio director reconoció como su película más completa ${ }^{93}$, esto es, una obra de arte total que marcó un hito dentro de la cinematografía en España. Así quedó patente en el éxito que tuvo la película, que fue el último estreno antes del inicio de la Guerra Civil. El film se siguió proyectando y estrenando durante la contienda en ambos lados del frente, e incluso en la posguerra. En algunas ciudades se siguió emitiendo hasta 1948, a la vez que su música se pudo escuchar por la radio ${ }^{94}$; posiblemente, debido a la falta de películas y a que prevaleció su carácter alegre, divertido y de entretenimiento sobre otras consideraciones.

La actividad de Marquina y Feduchi, al igual que su película, prosiguió en años posteriores en un contexto muy diferente como fue la guerra y la posterior dictadura. Los dos siguieron vinculados al mundo del cine y coincidieron en un ámbito nuevo para ambos como fue la docencia. Durante la guerra Marquina trabajó para el departamento cinematográfico franquista y, más tarde, se trasladó a Argentina hasta que finalizó la contienda. A su regreso trabajó como director de la productora CIFESA (Compañía Industrial Film Española, S.A.), y a partir de 1942 empezó a dar clases de cine en la Escuela de Ingenieros Industriales de Madrid ${ }^{95}$, que en 1947 acogió el Instituto de Investigaciones y Experiencias Cinematográficas (IIEC) en el que impartió la asignatura de "Producción, tecnología y montaje". En 1955 creó su propia productora, CIA, dirigió más obras, a la vez que colaboró con la radio y la televisión.

Paralelamente, durante la guerra Feduchi trabajó para la Junta del Tesoro Artístico de Madrid en la custodia, catalogación y estudio de mobiliario. Seguidamente, prosiguió su trabajo como diseñador, vinculado a la empresa Rolaco de la que fue director artístico, y como encargado de la decoración de otros filmes, a la vez que fue profesor de "Escenotecnia" en la en el IIEC, donde compartió las aulas con Marquina ${ }^{96}$. En estos años su obra siguió la estética oficial del régimen hasta que, a partir de la década de los cincuenta, se aproximó a la modernidad ${ }^{97}$. De forma paralela, escribió numerosos libros sobre mobiliario, en los que encontramos algunas de las premisas que siguió en sus obras y aplicó a "El bailarín y el trabajador"98. En ellos subrayó que cada problema requería de una solución distinta, pero que los muebles se trataban como los edificios, siguiendo la proporción y el equilibrio de las masas. Asimismo, apuntó la importancia de la sencillez, la relevancia de los materiales, el sentido de proporción, la armonía de los colores y el equilibrio entre los muebles y el espacio ${ }^{99}$. 


\section{NOTAS}

${ }^{1}$ Fco. Javier Muñoz-Fernández es profesor de la UPV/EHU y este trabajo se inscribe dentro del grupo de investigación: "Demografía histórica e historia urbana" GIU18/114 de la UPV/EHU. ${ }^{2}$ Jesús García Dueñas y Jorge Gorostiza, coord., Cuadernos de la Academia, monográfico "Los estudios cinematográficos españoles" 10 (2001). Pedro Delgado Cavilla, "Estudios," en Diccionario del cine iberoamericano. España, Portugal y América, dir. Carlos F. Heredero y Eduardo Rodríguez Merchán (Madrid: SGAE, 2011), 600-633. Román Gubern, "El cine sonoro (1930-1939)," en Historia del cine español (Madrid: Cátedra, 2009), 123-180. Josetxo Cerdán, "Las patentes de cine sonoro en España: un primer paso hacia la conquista del mercado (19261932)," en El paso del mudo al sonoro en España, coord. Joan M. Minguet y Julio Pérez Perucha (Madrid: UCM, 1994), 57-70. Mario Arnold, "La CEA es un barco brujo," Cinegramas 5, 14 de octubre, 1934, s.p.

${ }^{3}$ Rafael Utrera, Escritores y cinema en España. Un acercamiento histórico (Madrid: Ediciones JC, 1985), 61. Rafael R. Tranche, “(1934-1969) CEA: los intereses creados," Cuadernos de la Academia 10 (2001), 135-150.

${ }^{4}$ Daniel Sánchez Salas, "Marquina Pichot, Luis," en Diccionario del cine iberoamericano. España, Portugal y América, 479-482.

${ }^{5}$ Se llegaron a estrenar veintiuna películas de este género, entre las que destacaron "Boliche" (1933), "El negro que tenía el alma blanca" (1934) o la ya citada "Rumbo al Cairo" (1935). José María Caparrós, Arte y política en el cine de la República (Barcelona: Universitat de Barcelona, 1981), 265.

${ }^{6}$ Publicidad de la película, Cinegramas 55, 29 de septiembre, 1935, s.p.

7 "A veces me entrometía descaradamente en la dirección," Luis Buñuel, Mi último suspiro (Barcelona: Random House Mondadori, 2012), 180. En 1925 Manuel Noruega llevó la obra teatral por vez primera al cine y en 1950 lo hizo Luis Buñuel bajo el título "La hija de engaño: Don Quintín, el amargao". Sobre Filmófono se puede consultar: Julio Cela, "La empresa cinematográfica española Filmófono (1929-1936)," Documentación de la Ciencias de la Información 18 (1995), 59-85. Julio Pérez Perucha, Cine español. Algunos jalones significativos (18961936) (Madrid: Films 210, 1992), 44. Luis Fernández Colorado, "Buñuel, Urgoiti y Filmófono," Archivos de la Filmoteca 34 (2000), 26-38. Ian Gibson, Luis Buñuel. La forja de un cineasta universal, 1900-1938 (Barcelona: Penguin Random House, 2016), 602-610, 623-630.

${ }^{8}$ El 2 de mayo en el teatro Campos Elíseos de Bilbao, el 11 de mayo en el cine Rialto de Valencia, el 13 de mayo en el cine Doré de Zaragoza y el 21 de mayo en el cine Capitol de Madrid. "Publicidad," El Pensamiento Alavés, 27 de abril, 1936; "Cameraman. Teatro Príncipe. El bailarín y el trabajador," Libertad, 30 de abril, 1936; "Publicidad," Heraldo de Castellón, 28 de abril, 1936; Juan B. Heinik y Alfonso C. Vallejo, Catálogo del cine español. Films de ficción 1931-1940. Volumen F-3 (Madrid: Cátedra, Filmoteca Española, 2009), 48-49.

9 "En la CEA. Un film de Benavente," La Época, 15 de febrero, 1936; "En la CEA. Un film de Benavente," La Libertad, 15 de febrero,1936; "En la CEA. Un film de Benavente," Heraldo de Madrid, 16 de febrero, 1936; "El bailarín y el trabajador," La Nación, 29 de febrero, 1936; "El bailarín y el trabajador," El Sol, 1 de marzo, 1936; Bernabé de Aragón, "Cinelandia," Mundo Gráfico 1.272, 13 de mayo, 1936, s.p.; “Guía del espectador,” ABC, 5, 8, 16 y 21 de mayo, 1936. ${ }^{10}$ Declaraciones de Enrique Domínguez Rodiño recogidas en Florentino Hernández-Girbal, "Viendo rodar 'El bailarín y el trabajador'," Cinegramas 79, 15 de marzo, 1936, s.p. En una época en la que se reclamaban nuevos directores: F. Hernández-Girbal, "El cine español necesita directores," Cinegramas 9, 11 de noviembre, 1934, s.p.

${ }^{11}$ Declaraciones de Luis Marquina realizadas en 1943 y recogidas en Julio Pérez Perucha, El cinema de Luis Marquina (Valladolid: 28 Semana Internacional de Cine de Valladolid, 1983), 127-129. Declaraciones de Luis Marquina recogidas en Florentino Hernández-Girbal, "Viendo 
rodar 'El bailarín y el trabajador,", s.p. Declaraciones de Luis Marquina recogidas en Antonio de Jaén, "Directores a examen," Cinegramas 88, 17 de mayo, 1936, s.p.

12 Jacinto Benavente, Obras completas (Madrid: Aguilar, 1962), 1.037-1.086. En 1942 Luis Marquina llevó al cine otra obra del escritor: "Vidas cruzadas". Rafael Utrera, Escritores y cinema en España, 61. María del Pilar Espín Templado, "Jacinto Benavente, autor de género chico," en La zarzuela de cerca, ed. Andrés Amorós (Madrid: Espasa Calpé, 1997), 163-205.

${ }^{13}$ Publicidad de la película "El bailarín y el trabajador". C2-F2. A1.2. Archivo de la Filmoteca Española.

${ }^{14}$ Declaraciones de Luis Marquina recogidas en Florentino Hernández Girbal, "Viendo rodar El Bailarín y el trabajador," s.p. Benavente aparece como dialoguista en los trabajos de Juan B. Heinkik y Alfono C. Vallejo, y Josetxo Cerdán. No obstante, María del Mar Mañas duda de ello y atribuye a Marquina los diálogos adicionales. Juan B. Heinkik y Alfonso C. Vallejo, Catálogo del cine español. Films de ficción 1931-1940. Volumen F-3 (Madrid: Cátedra, Filmoteca Española, 2009), 48-49. Josetxo Cerdán, "El bailarín y el trabajador," en Antología crítica del cine español (1906-1995), ed. Julio Pérez Perucha (Madrid: Cátedra, 1997), 104. María del Mar Mañas Martínez, "El Bailarín y el trabajador de Luis Marquina: adaptación cinematográfica de Benavente a ritmo de musical," en La otra Edad de Plata. Temas, géneros y creadores (1898-1936), ed. Ángela Ena Borbonada (Madrid: Universidad Complutense de Madrid, 2013), 291-311.

${ }^{15}$ Fig.01: Si considera que la exhibición de este material infringe cualquiera de sus derechos o intereses legítimos, por favor, póngase en contacto con nosotros para que, en caso de tratarse de un requerimiento legítimo y fundamentado, procedamos a retirar dicho material o busquemos una solución equitativa.

${ }^{16}$ Declaraciones de Luis Marquina recogidas en Antonio de Jaén, "Directores a examen," s.p. Declaraciones de Luis Marquina recogidas en Florentino Hernández Girbal, "Tras la cámara," s.p. ${ }^{17}$ En 1936 la editorial Bistagne de Barcelona editó dentro de su colección "La novela semanal cinematográfica" el volumen correspondiente a la película: El bailarín y el trabajador (Barcelona: Editorial Bistagne, 1936), 50.

${ }^{18}$ Publicidad del film. C2. F2. A1.2. Archivo de la Filmoteca Española. Así lo corroboró parte de la crítica: "La pantalla. El bailarín y el trabajador," La Gaceta del Norte, 3 de mayo, 1936.

19 "Del rodaje de 'El bailarín y el trabajador'. Antoñita Colomé cantante," La Voz, 28 de marzo, 1936; "Guía del espectador," ABC, 3 de mayo, 1936, "Producción nacional," Cinema Sparta 31 (15 de febrero de 1936), s.p. "El bailarín y el trabajador," $E l$ Sol, 1 de marzo de 1936. "El Cine," El Sol, 3 de mayo de 1936, "Las grandes películas de Hispania Tobis," Tabacos 47 (febrero de 1936),32, "El bailarín y el trabajador," Heraldo de Madrid, 29 de febrero de 1936, "La producción nacional. Los estrenos durante el mes de mayo. El bailarín y el trabajador," Cine Español 28, (junio 1936), 2. ${ }^{20}$ Además de las ya citadas, también se anotó la participación de Irene Caba Alba, Mariano Ozores y Enrique Guitart. La mayoría de ellos fueron actrices y actores de teatro, más o menos conocidos, que prosiguieron su carrera profesional en el cine. José Luis Borau dir., Diccionario del cine español (Madrid: Alianza. Academia de las Artes y las Ciencias Cinematográficas de España, 1998), 241, 267-268, 748-749.

${ }^{21}$ Publicidad del film. C2-F2. A1.2. Archivo de la Filmoteca Española.

${ }^{22}$ Además, los musicales no eran nuevos en el cine. En 1925 alrededor de un $20 \%$ de la producción cinematográfica fueron zarzuelas que en su proyección se acompañaron de música en directo. Así sucedió con "La Bejarana" (1925, Eusebio Fernández Ardavín), escrita por Alonso en colaboración con Emilio Serrano y con libreto de Luis Fernández Ardavín. Celsa Alonso, "De la zarzuela y la revista a la música de cine: el maestro Francisco Alonso y el cine de la República," en Reflexiones en torno a la música y la imagen desde la musicología española, ed. Matilde Olarte Martínez (Salamanca: Plaza Universitaria Ediciones, 2009), 305-332. Jean-Claude Seguin, Historia del cine español (Madrid: Acento Editorial, 1995), 15. 
${ }^{23}$ Entre sus obras destacaron: "La parranda" 1928, "La picarona" 1930, "Las castigadoras" 1927, "Las aviadoras" y "Las Cariñosas" 1928, "Las leandras" 1931 que lanzó al estrellato a Celia Gámez, así como "Las de armas tomar," "Mujeres de fuego" o la exitosa "Me llaman la presumida" todas ellas de 1935.

${ }^{24}$ Celsa Alonso, Francisco Alonso: otra cara de la modernidad (Madrid: UCM, 2014), 476. Josetxo Cerdán, "Las patentes del cine sonoro en España. Un primer paso hacia la conquista del mercado (1926-1932)," 57-70.

${ }^{25}$ Alonso, "De la zarzuela y la revista a la música de cine," 331; Mañas Martínez, "El bailarín y el trabajador," 294.

${ }^{26} \mathrm{El}$ ingeniero Lucas de la Peña fue el encargado del sonido de la película. Marco Antonio Juan de Dios Cuartas, "El auge de los estudios cinematográficos durante la Segunda República: una propuesta de análisis del diseño sonoro de El bailarín y el trabajador (1936)," Cuadernos de etnomusicología 11 (2018), 21-53.

27 "Dos técnicas para un arte," $E l$ Sol, 31 de mayo, 1936.

${ }^{28}$ Antonio Barbero reconoció que se alejaba de propuestas musicales como el "Sombrero de copa" (1935) de Mark Sandrich ya que la música, al tratarse como si fuese una obra de teatro, rompía el ritmo de la película, idea con la que coincidió Antonio Guzmán, pero que no compartió Juan Antonio Cabezas. "La producción nacional. Los estrenos durante el mes de mayo. El bailarín y el trabajador," Cine Español 28 (junio 1936), 2. Antonio Barbero, "El bailarín y el trabajador (crítica)," ABC, 22 de mayo, 1936. Antonio Guzmán Merino, "La semana cinematográfica," Cinegramas 90, 31 de mayo, 1936, s.p. S. A. Micon, "El bailarín y el trabajador," Ahora, 22 de mayo, 1936. Juan Antonio Cabezas, "Dos técnicas para un arte," El Sol, 31 de mayo, 1936.

${ }^{29}$ Guzmán Merino, "La semana cinematográfica," s.p.

${ }^{30}$ Guillermo de Torre, Literaturas europeas de vanguardia (Sevilla: Renacimiento, 2001), 407 yss.

31 "Guía del espectador," ABC, 23 de mayo, 1936, "El bailarín y el trabajador se estrenará en el Capitol," El Sol, 17 de mayo de 1936. "El gran éxito español," El Sol, 31 de mayo de 1936.

${ }^{32}$ Bernabé de Aragón, "Cinelandia," Mundo Gráfico 1.282, 27 de mayo,1936, s.p.

${ }^{33}$ Bernabé de Aragón, "Cinelandia," Mundo Gráfico 1.283, 3 de junio, 1936, s.p.

${ }^{34}$ Juan Antonio Cabezas, "Dos técnicas para un arte," El Sol, 31 de mayo, 1936.

${ }^{35}$ El bailarín y el trabajador, 18.

${ }^{36}$ Ramón Gómez de la Serna, Ismos (Madrid: Biblioteca Nueva, 2002), 158 y ss.

${ }^{37}$ También cabría recordar "El hombre y la técnica" (1931) de Osvald Spengler. "Tiempos modernos" se estrenó el 16 de enero en Nueva York y seguidamente en España.

${ }^{38}$ Declaraciones de Marquina recogidas en Antonio de Jaén, "Directores a exámen”, s.p., y Julio Pérez Perucha, El cinema de Luis Marquina, 128.

${ }^{39}$ José Díaz Fernández, La Venus mecánica (Madrid: Asociación de Libreros de Lance de Madrid, 2012).

${ }^{40}$ Existe un fragmento del film on-line en el que se pueden apreciar algunos de los muebles y decorados: “El bailarín y el trabajador," RTVE, consultado el 1 de abril de 2020: https://www. rtve.es/alacarta/videos/historia-de-nuestro-cine/historia-nuestro-cine-bailarin-trabajador-presentacion/3354341// [00:47- 1:38 min.].

${ }^{41}$ Ángel Urrutia, Arquitectura española del siglo XX (Madrid: Cátedra, 1997), 327-328. Selina

Blasco, "Pesquisas, recuerdos y una entrevista," en Feduchi. Tres generaciones en arquitectura $y$ diseño (s.l.: Feria de Valencia, 2009), 9-32.

${ }^{42}$ Ángel Urrutia, Arquitectura española, 327. Luis M. Feduchi, Itinerarios de arquitectura popular española (Barcelona: Blume, 1974).

${ }^{43}$ Luis M. Feduchi, "Parador Nacional de Oropesa (Toledo)," Revista Nacional de Arquitectura 84 (1948), 479-480. 
44 "Interior de la tienda Philips Ibérica," Arquitectura 147 (1931), 244. "Tienda nueva en la avenida de Pi y Maragall," Arquitectura 147 (1931), 245. "Hotel particular, Madrid," Arquitectura 152 (1931), 414-415. "Un hotel particular en el parque metropolitano: Madrid," Obras 3 (1931), 65-72.

45 "Concurso privado. Solar Carrión en la plaza de Callao," Arquitectura 146 (1931); "Arquitectura comercial española. El edificio Carrión de Madrid," Nuevas Formas 1 (1935), 25-49; "Madrid. El edificio Carrión," Arquitectura 1 (1935), 2-32. En el concurso participaron Pedro Muguruza, Luis Gutiérrez Soto, Manuel Cárdenas, Eduardo Garay y Juan de Zavala, así como Emilio Paramés y José M. Rodríguez Cano.

46 "Ante el homenaje al creador del Capitol," Cinegramas 4, 30 septiembre, 1934, s.p.

${ }^{47}$ Urrutia, Arquitectura española, 329-330. Oriol Bohigas, Modernidad en la arquitectura de la España republicana (Barcelona: Tusquets, 1998), 130. Javier Pérez Rojas, Art deco en España (Madrid: Cátedra, 1990), 604-607.

${ }^{48}$ Se ha apuntado la relación con varios cines de Berlín: Litchburg de Rudolf Fränkel, Universum de Erich Mendelsohn o el Capitol de Hans Poelzig, así como el edificio del Berliner Tageblatt también de Mendelsohn. Javier Pérez Rojas, Art deco en España, 606. Ignacio Benlliure Feduchi, "El edificio Carrión. El cine Capitol," en Arquitectura de cine, eds. Daniel Villalobos, Sara Pérez e Iván Rincón (Valladolid: fundación docomomo ibérico. UVA), 65-107.

49 "Un justo homenaje. Ante el homenaje al creador del Capitol," Cinegramas 3, 23 de septiembre, 1934, s.p.

${ }^{50}$ Ibídem.

51 "Ante el homenaje al creador del Capitol," s.p.

${ }^{52}$ Juan Daniel Fullaondo, Los muebles del Capitol (Madrid: BD ediciones, 1980); Feduchi. Tres generaciones en arquitectura y diseño (s.l.: Feria de Valencia, 2009); María Villanueva Fernández y Héctor García-Diego Villarías, "Una aventura empresarial en un proyecto integral: mobiliario del edificio Capitol, Luis M. Feduchi, 1931-33,” Res Mobilis 7 (2017), 96-116. Julio Capella y Joaquín Larrea, Nuevo diseño español (Barcelona: Gustavo Gili, 1991), 19. María Jiménez de la Nava, "Rolaco: estudio histórico de la marca" (Trabajo de fin de grado, UPM, 2017).

${ }^{53}$ José María Tomás Llavador, "Feduchi. Tres generaciones en arquitectura y diseño," en Feduchi. Tres generaciones de arquitectura y diseño, 5-6. Rolaco se encargó de la decoración de obras realizadas por Luis Gutiérrez Soto, Luis Blanco Soler, Carlos Arniches y Martín Domínguez o Agustín Aguirre. Al respecto se puede consultar: Luis Feduchi, "Breve historia de Rolaco," Experimenta 20 (1998), 16-32. Carmen Espegel, "El nuevo espacio interior. La vanguardia del interiorismo español de los años treinta," Experimenta 28 (1998), 15-32. Miguel Ángel Baldellou, Luis Gutiérrez Soto (Madrid: Electa, 1997); Silvia Arbaiza Blanco-Soler, Luis Blanco Soler. Tradición y Modernidad (Madrid: Fundación Ramón Aceres, 1999); Manuel Serrano Marzo, "El mobiliario de la Ciudad Universitaria," en La Ciudad Universitaria de Madrid I (Madrid: COAM, UCM, 1988), 221-234. Pedro Feduchi Canosa, "Niquelados impecables con tintas clásicos. Muebles e interiores de la facultad," en La Facultad de Filosofía y Letras de Madrid durante la Segunda República (Madrid: SECC. Ayuntamiento de Madrid. COAM, 2008), 145-163. Concha Díez-Pastor, Carlos Arniches y Martín Domínguez, Arquitectos de la generación del 25 (Madrid: Mairea 2005); Pablo Rabasco y Martín Domínguez Ruz eds., Arniches y Domínguez (Madrid: Museo ICO. Akal, 2017); María Villanueva y Héctor GarcíaDiego, "Arquitectura, mobiliario y proyecto pedagógico: el pabellón de la residencia de señoritas estudiantes, 1932-1933," Ra 10 (2019), 87-96; Julia Galán et al., El diseño industrial en España (Madrid: Cátedra, 2010), 81.

54 "La casa de Mr. Brandon amueblado por Santamaría," Viviendas 12 (junio 1933), portada y 16-19; "Publicidad," Nuevas Formas 3 (1934), s.p.; "Santa María," Nuevas Formas 4 (1934), 208-216; "Muebles modernos y tendencias retrospectivas," Nuevas Formas 5 (1934), 266-267; 
"Proyecto de alcoba. Proyecto de salón. Arquitecto Galíndez (Bilbao)," Nuevas Formas 1 (1935), s.p; "Banco de España. José Yárnoz," Nuevas Formas 10 (1935-1936), 518-527.

55 "Muebles modernos y tendencias retrospectivas," 266-267.

56 "Cine actualidades en Zaragoza," Nuevas Formas 7 (1935-1936), 380-381.

${ }^{57}$ Junto con Santamaría colaboró en obras de Leandro Navarro, Martínez Sierra y J. Luca de Tena. Selina Blasco, "Feduchi. Dos biografías y un curriculum," en Feduchi. Tres generaciones en arquitectura y diseño, 69.

58 "Decorados para un film. Escenografía y muebles: Santa María y Feduchi," Nuevas Formas 1 (1935), 46-47.

${ }^{59}$ Cinegramas, 15 de marzo, 1936.

${ }^{60}$ Heinkik y Vallejo, Catálogo del cine español, 48-49.

${ }^{61}$ Declaraciones de Luis Marquina recogidas en Antonio de Jaén, "Directores a examen": s.p.

${ }^{62}$ Heinkik y Vallejo, Catálogo del cine español, 48-49.

${ }^{63}$ Ibídem.

${ }^{64}$ Inicialmente solo contaba con uno y el resto se fueron creando de manera paulatina para dar respuesta a la demanda de la época. A.R. Barbeito, "La producción en los cines españoles. Nuestras interviús. El consejero-delegado de la CEA habla para Sparta," Sparta 11, 30 de enero, 1935, 6; Dios Cuartas, "El auge de los estudios cinematográficos," 36.

65 "La producción nacional. Los estrenos durante el mes de mayo. El bailarín y el trabajador," Cine Español 28 (junio de 1936), 2.

${ }^{66}$ Hernández-Girbal, "Viendo rodar," s.p.

${ }^{67}$ Llama la atención del nombre del local en plena República, como también que las galletas Romagosa tuvieran éxito entre la monarquía, tal como se señala en la "Marcha de las galletas": "venga tenemos otras marcas, ministros y monarcas se surten aquí".

${ }^{68}$ En este sentido sigue las indicciones de la obra teatral: "En una galería de un Casino de playa veraniega". Benavente, Obras completas, 1041.

${ }^{69}$ Luis M. Feduchi, La casa por dentro II (Madrid: Afrodisio Aguado, 1948), 99. Sobre el mobiliario de esta época se puede consultar: Paolo Sustersic, "La Bauhaus y la batalla por el interior moderno en España: éxito, crisis y alternativas," en Bauhaus in and out. Perspectivas desde España, eds. Laura Martínez de Guereñu y Carolina B. García-Estevez (Madrid: AhAU, 2019), 494-506, Francisco Javier Muñoz Fernández, "Las sillas de Aizpúrua y Labayen: la asimilación de un nuevo mobiliario y una nueva arquitectura," Artigrama 33 (2018), 387-406. Mercè Vidal, "Mediterranisme en el Disseny des anys trenta i la seva pervivencia alsanys de postguerra," en La formació del sistema Disseny Barcelona (1914-2014) un camí de modernidat, coord. Anna Calvera (Barcelona: Universitat de Barcelona, 2014), 205-239. Alícia Suárez, "L’Exposició Internacional del Moble de Barcelona (1923) i la bellesa de la Llar Humil," en La formació del sistema Disseny Barcelona, 105-116. Paolo Sustersic, "Entre la máquina y el pueblo. El diseño de mobiliario e interiores en el entorno del GATCPAC," en GATCPAC. Una nueva arquitectura para una nueva ciudad, eds. Antonio Pizza y Josep M. Rovira (Barcelona: Museu d'Història de Barcelona, 2006), 308-322. Rosa M. Subirana, "El mobiliario del GATCPAC. Joan Baptista Subirana," DC 12-13(2005), 110-119. Raimón Torres, "Los diseños de Josep Torres Clavé y el GATCPAC," en Josep Torres Clavé (Barcelona: Santa \& Cole. UPC, 1994), 11-20.

${ }^{70}$ Erick Dieckmann, "Junco y acero," Viviendas 5 (1932), 32-33. "Muebles de verano," Viviendas 11 (1933), 20-21. Feduchi también corroboró que los muebles de mimbre o madera fueron corrientes en terrazas y áticos. Lui M. Feduchi, La casa por dentro II, 99.

${ }^{71}$ Asimismo, a partir de 1931 la empresa se anunció en la programación del Teatre del Liceu de Barcelona. Gran Teatro del Liceo. Programa Oficial. Temporada 1931-32 (s.l: Servicios gráficos y de publicidad Catalunya). Dámaso Azcue. C32/212. Arxiu Històric del Col.legi Oficial d'Arquitectes de Catalunya. 
${ }^{72}$ También aparece otra silla de similares características que no hemos podido identificar. "Sección de noticias. La Feria de muestras de Barcelona," AC 10 (1933), 40; Gran Teatro del Liceo (Barcelona: Imprenta L’Estampa, 1934) (Aida, El Barbero de Sevilla, Las Bodas de Fígaro, El Caballero de la Rosa, El Matrimonio Secreto, Las Golondrinas, Los Maestros Cantores de Nuremberg, I Puritani). "Pequeñas casas para el fin de semana," AC 19 (1935), 32-42, "Dos estudios de artistas españoles," Nuevas Formas 5 (1935), 276-277.

${ }^{73}$ Así lo apuntan también María Villanueva y Héctor García-Diego, "La silla del GATEPAC: un viaje colectivo de ida y vuelta," Proyecto, Progreso, Arquitectura 11 (2014), 40-51.

${ }^{74}$ Otra versión de esta silla en madera (B751 de Émile Guillot, 1928) se había utilizado en la casa-estudio de Sert en Barcelona (1931), en la casa desmontable para el fin de semana del GATCPAC (1932), el stand del grupo en la feria de muestras de Barcelona de 1933, o el estudio de Rodríguez Arias (1935). "Casa de alquiler. Calle de Muntaner, Barcelona. Arquitecto. J. Luis Sert," AC 4 (1931), 16-19, "La casa para el fin de semana (week-end)," AC 7 (1932), 18-23, "Mobiliario standard tipos GATEPAC," AC 8 (1932), 26-27. "Sección de noticias," AC 10 (1933), 40. Arquitectura contemporánea en España. Tomo III. Grupo de arquitectos y técnicos españoles para el progreso de la arquitectura contemporánea (Madrid: Edarba, 1935), 95-104.

75 “El edificio Carrión,” Arquitectura 1 (1935), 1-32.

${ }^{76}$ Villanueva y García-Diego, "La silla del GATEPAC: un viaje colectivo de ida y vuelta,”; Muñoz Fernández, "Las sillas de Aizpúrua y Labayen," 387-406.

${ }^{77}$ Hernández-Girbal, "Viendo rodar," s.p.

78 "Raza," consultado el 30 de marzo de 2020: https://www.rtve.es/alacarta/videos/filmoteca/ raza-1941/3336985/ (minuto 26:01).

${ }^{79}$ Hernández-Girbal, "Viendo rodar," s.p.

${ }^{80}$ En la película se intercalan escenas de la fábrica recreada en los estudios con la fábrica real con el fin de que el espectador asistiera "como en un documental, a la complicada elaboración de la sabrosa mercancía," "El bailarín y el trabajador," Heraldo de Madrid, 29 de febrero, 1936.

${ }^{81}$ Más concretamente se puede identificar el sillón de bar realizado para el Capitol con un tapizado diferente.

82 También aparece otra cómoda de líneas más severas. La cómoda curvada se publicó en Nuevas Formas 1 (1935), 48. En 1947 Feduchi apuntó la cómoda como un mobiliario adecuado para los salones para rellenar los huecos de la pared. Luis M. Feduchi, La casa por dentro I (Madrid: Afrodisio Aguado, 1947), 20.

${ }^{83}$ Luis M. Feduchi, Antología de la silla española (Madrid: Afrodisio Aguado, 1957), Figs. 122, 139, 140 y 99. Luis M. Feduchi, Historia del mueble (Madrid: Afrodisio Aguado, 1946), Fig. 996, 998, 999, 1.073, 1.074, 1.075. Luis M. Feduchi, El mueble español (Barcelona: Ediciones Polígrafa, 1969), Fig.194, 248. Feduchi recogió las propuestas como modelos de su obra: La casa por dentro $I, 23,32,35,63,68$.

84 "Nuevas tendencias del mueble español. Realizaciones de los decoradores Santa María y Feduchi," Nuevas Formas 1 (1936-1937), 30-42.

${ }^{85}$ Asimismo, nos podría recordar a varios modelos recogidos en Luis M. Feduchi, El mueble español, Fig.224, 226 y Luis M. Feduchi, Historia del mueble, Fig.1.062.

${ }^{86}$ Luis M. Feduchi, Historia del mueble, Fig.1.078 y 1.079. Museo Romántico de Madrid. CE0293 (c.1840) y CE0268 (c.1833-1843).

${ }^{87}$ Luis M. Feduchi, La casa por dentro I, 30, 26.

${ }^{88} \mathrm{El}$ acolchado de la cama apareció en un diseño del arquitecto Manuel I. Galíndez que realizó Santamaría, y también está presente en otras propuestas europeas de la época. "Proyecto de alcoba. Arquitecto Galíndez (Bilbao)," Nuevas Formas 1 (1935), s.p. "Decoración de un piso en una casa de alquiler en Bélgica," Nuevas Formas 8 (1935/1936), 434-437.

${ }^{89}$ La escena del dormitorio se puede visionar en: "El bailarín y el trabajador," Mercury Films, consultado el 6 de abril de 2020, https://videomercury.com/catalogo/pelicula/?idpelicula=1478. 
Años más tarde Feduchi apuntó que si los dormitorios contaban con un mirador en este espacio se podía colocar un rincón de estar o la zona de tocador. Feduchi, La casa por dentro I, 113.

90 "El gran éxito español," El Sol, 31 de mayo, 1936. Bernabé de Aragón, "Cinelandia," Mundo Gráfico 1.283, 3 de junio, 1936, s.p.

${ }^{91}$ Rafael Gerona, "Cines y películas," ABC, 28 de mayo, 1936.

92 "El nuevo film de Luis Marquina," La Voz, 18 de julio, 1936.

${ }^{93}$ Declaraciones recogidas en Julio Pérez Perucha, El cine de Luis Marquina, 128.

${ }^{94}$ Así se constata en las referencias que hemos consultado en la prensa y publicaciones periódicas de la época, al menos en Cáceres (1936-1937), Murcia (inicialmente en la radio y más tarde en el cine, 1936-1937), Córdoba (1936-1939), Santa Cruz de Tenerife (1936-1937), Vitoria (19371938), Santander (1937), Zamora (inicialmente en el cine y posteriormente en la radio, 19371943), Gijón (1937), Castellón (1937), Salamanca (1937), Alicante (1937), Lugo (1937), Madrid (1937-1941), Toledo (1937), Granada (1938), Ferrol (1938), Palencia (1938-1940), Barcelona (1939-1944), Guadalajara (1939), Mahón (1939) y Burgos (1942-1948).

${ }^{95}$ Lo hizo en colaboración con Victoriano López García y Antonio Colino. Victoriano López García y Luis Marquina Pichot, Lecciones sobre cinematografía (Curso académico 1941-1942) (Madrid: Escuela Especial de Ingenieros Industriales, 1942).

${ }^{96}$ Se trató de las películas: "Don Floripondio" (1939) y "Tierra y cielo" (1941) de Eusebio Fernández Ardavín, "Raza" (1941) y "Correo de indias" (1942) ya citadas. Luis M. Feduchi, "Escenotecnia y cine," Revista Nacional de Arquitectura 117 (1951), 23-31.

${ }^{97}$ Realizó propuestas centradas en lo clásico y lo popular, tal como lo reflejan sus trabajos para la Obra Nacional de Artesanía, Auxilio Social y los castillos de la Mota y las Navas de la Sección Femenina. De igual forma, colaboró con distintos artesanos para que renovaran sus repertorios a partir de los diseños realizados por él, a la vez que se encargó de la construcción y la decoración de varios edificios. La modernidad quedó patente en su propuesta de silla de tubo y plástico de 1955: "Una silla de tubo y plástico," Revista Nacional de Arquitectura 157 (1955), 37-38.

${ }^{98}$ Luis M. Feduchi, Interiores (Madrid: Afrodisio Aguado, 1951); Luis M. Feduchi, Interiores de hoy (Madrid: Afrodisio Aguado, 1955), Luis M. Feduchi, El mueble (Madrid: Patrimonio Nacional, 1965); Luis M. Feduchi, Estilo del mueble español (Madrid: Abantos, 1969), junto otras obras además de las ya citadas.

${ }^{99}$ Luis M. Feduchi, Historia del mueble, 217-218. Luis M. Feduchi, La casa por dentro I, 14. Luis M. Feduchi, La casa por dentro II, 14. 